\title{
Univariate Versus Multivariate
} Modeling of Panel Data: Model

\author{
Juan Carlos Bou' and Albert Satorra ${ }^{2,3}$
}

\begin{abstract}
Two approaches are commonly in use for analyzing panel data: the univariate, which arranges data in long format and estimates just one regression equation; and the multivariate, which arranges data in wide format, and simultaneously estimates a set of regression equations. Although technical articles relating the two approaches exist, they do not seem to have had an impact in organizational research. This article revisits the connection between the univariate and multivariate approaches, elucidating conditions under which they yield the same-or similar-results, and discusses their complementariness. The article is addressed to applied researchers. For those familiar only with the univariate approach, it contributes with conceptual simplicity on goodness-of-fit testing and a variety of tests for misspecification (Hausman test, heteroscedasticity, autocorrelation, etc.), and simplifies expanding the model to time-varying parameters, dynamics, measurement error, and so on. For all practitioners, the comparative and side-by-side analyses of the two approaches on two data setsdemonstration data and empirical data with missing values-contributes to broadening their perspective of panel data modeling and expanding their tools for analyses. Both univariate and multivariate analyses are performed in Stata and R.
\end{abstract}

\section{Keywords}

structural equation modeling, longitudinal data analysis, quantitative research, multiple regression, multivariate analysis

Panel data are widely used in social and behavioral sciences such as economics, organizational research, and applied psychology. They offer researchers theoretical and methodological advantages

\footnotetext{
'Department of Business Administration and Marketing, Universitat Jaume I, Castellón, Spain

${ }^{2}$ Department of Economics and Business, Universitat Pompeu Fabra, and Barcelona GSE, Spain

${ }^{3}$ BI Norwegian Business School, Oslo, Norway
}

Corresponding Author:

Juan Carlos Bou, Department of Business Administration and Marketing, Universitat Jaume I, Avinguda Sos Baynat s/n, I207I

Castelló, Spain.

Email: bou@uji.es 
over cross-sectional data: Panel data allow the analysis of dynamic effects (effects among variables over time; Bergh, 1993; Greve \& Goldeng, 2004; Pitariu \& Ployhart, 2010); provide a way to control for unmeasured stable variables (the so-called unobserved heterogeneity in the econometric literature); and can address some sources of endogeneity of regressors (Hamilton \& Nickerson, 2003) that prevent estimates from being interpreted as causal effects (Antonakis, Bendahan, Jacquart, \& Lalive, 2010).

In the panel data literature two apparently distinct modeling approaches are in use: the univariate approach, where observations are stacked across units and time (so a unit generates as many rows as time points observed in the panel) and just one regression equation is estimated; and the multivariate approach, where each unit generates a single row of data (and each time-varying variable generates a different column for each time point) and a set of regression equations — one for each time point — is estimated simultaneously.

The univariate approach to panel data is extensively described in classic econometric manuals (e.g., Arellano, 2003, chaps. 2-3, 7-8; Baltagi, 2013, chaps. 2-5; Greene, 2003, chap. 13; Hsiao, 2014, chaps. 3-4; Wooldridge, 2013, chap. 14). It is also present in behavioral sciences and organizational research (Bliese \& Ployhart, 2002; Holcomb, Combs, Sirmon, \& Sexton, 2010; Hom \& Haynes, 2007; Pedhazur, 1982; Rabe-Hesketh \& Skrondal, 2012, chaps. 3-6; Snijders \& Bosker, 2012, chap. 12). It encompasses both static models such as regression with random intercept, random coefficients models, growth models, and also dynamic models with lagged effects of dependent and independent variables (e.g., autoregressive models, finite distributed lag models). The multivariate perspective has a long tradition in social and behavioral sciences (e.g., Chamberlain, 1982; Davidson, 1972; O. D. Duncan, 1969; Finkel, 1995, chaps. 2-3, 5-6; Finn, 1969; Jöreskog, 1978; Markus, 1979, chaps. 3; Montfort, Oud, \& Satorra, 2007, chaps. 9-17; Rogan, Keselman, \& Mendoza, 1979). It is implicit in a variety of models discussed in the literature such as repeatedmeasures ANOVA (Bergh, 1995; O’Brien \& Kaiser, 1985), repeated-measures regression (Misangyi, LePine, Algina, \& Goeddeke, 2006), autoregressive panel models (Kessler \& Greenberg, 1981, chap. 7), cross-lagged regression models (Mayer, 1986; Rogosa, 1980), and latent growth curve (LGC) models (Bollen \& Curran, 2006, chaps. 2-3, 5, 7; Chou, Bentler, \& Pentz, 1998; T. E. Duncan \& Duncan, 1995; McArdle \& Epstein, 1987; Meredith \& Tisak, 1990; among others).

Recent research has investigated the relation between the univariate and multivariate approaches to panel data (Allison, 2009; Allison \& Bollen, 1997; Ejrnaes \& Holm, 2006; Teachman, Duncan, Yeung, \& Levy, 2001); more specifically, Bollen and Brand (2010) have made explicit the restrictions under which the multivariate formulation matches particular univariate panel data estimators. This literature, however, is a somewhat technical body of work addressed to users of structural equation modeling (SEM), and it is confined to social and political science methodologies; it does not seem to have had an impact in the organizational research arena. A literature review on some of the leading journals in organizational sciences (Academy of Management Journal, Journal of Applied Psychology, Journal of Management, and Strategic Management Journal) for the three years 2013, 2014, and 2015 returned 247 articles that explicitly involved the use of panel data. The vast majority of these articles, 216, used the univariate perspective for panel data analysis; specifically, they all estimated one regression equation based on the specification of a varying intercept and, in some cases, also lagged dependent and independent variables. Only 31 out of the 247 articles could be classified as using the multivariate perspective to panel data (cross-lagged models, LGC models, path analysis, and others). Clearly, the univariate perspective for panel data is dominant in organization research and related disciplines. None of the articles classified as univariate do not even mentioned the multivariate perspective as referred to by Bollen and Brand (2010) and others. ${ }^{1}$

We believe researchers using the univariate approach could benefit from knowing about the tools for estimation and model search in panel data that are readily available in the multivariate setup and implemented in current software. For organizational researchers familiar with the multivariate models discussed in the psychology and management literatures (e.g., Bollen \& Curran, 2006; Chan, 
Table I. The Long Format.

\begin{tabular}{lcrrr}
\hline Unit & Time & $x$ & $y$ & $z$ \\
\hline 1 & 1 & -0.34 & -4.53 & -1.42 \\
1 & 2 & -0.85 & -1.96 & -1.42 \\
1 & 3 & 0.05 & -2.17 & -1.42 \\
1 & 4 & 1.48 & 3.65 & -1.42 \\
2 & 1 & -0.85 & 0.42 & 0.22 \\
2 & 2 & 0.61 & 3.41 & 0.22 \\
2 & 3 & 0.06 & 4.39 & 0.22 \\
2 & 4 & 0.83 & 6.86 & 0.22 \\
$\vdots$ & & & & \\
3000 & 1 & 1.00 & 1.79 & 0.82 \\
3000 & 2 & 0.06 & 1.27 & 0.82 \\
3000 & 3 & 0.25 & 3.14 & 0.82 \\
3000 & 4 & -0.64 & -3.42 & 0.82
\end{tabular}

1998; T. E. Duncan, Duncan, \& Strycker, 2006; MacCallum, Kim, Malarkey, \& Kiecolt-Glaser, 1997; Ployhart \& Vandenberg, 2010), the present article will help to connect their models with the panel data models discussed in the econometric literature.

The present article discusses the two approaches to panel data side by side, focusing on the regression models with varying intercepts. In the comparison, we adopt a didactic, nontechnical approach, providing step-by-step guidance to applied researchers on how to estimate, compare, and modify the models in the univariate and multivariate approaches. Our aim is to help organizational researchers understand the comparative advantages and limitations of the two approaches, and to acquaint them with practical tools now available in the multivariate setup that they may not be aware of. We also feel that a more balanced view of the two approaches could help researchers widen their view of panel data modeling and broaden the range of tools for their analysis.

The article is structured as follows. Section 1 presents the long and wide format arrangement of panel data and their basic models. Section 2 presents the models: model conditions for the equality or divergence of the two approaches; and, by capitalizing on the multivariate approach, expansion of the family of models to include time-varying parameters, dynamics, and other extensions. Section 3 compares the two approaches using artificial data. In Section 4, through an illustration using empirical data, the two approaches tackle practical issues such as missing data and model specification. Section 5 concludes with a discussion.

\section{Long and Wide Formats}

In panel data, a set of variables are observed for each of $i=1,2, \ldots \mathrm{N}$ units (individuals, firms) repetitively at $t=1,2, \ldots, T$ time points. We have the time-varying variables (in our notation, $y$ and the $x \mathrm{~s}$ ), characteristics of the units that vary with time, and the time-invariant variables (the $z \mathrm{~s}$ ), characteristics of the units that remain constant across time. Panel data can be arranged in two different formats. In the long (or stacked) format each row corresponds to the values of a unit recorded at one time point, so a unit generates as many rows as time points observed in the panel. In the wide format, each unit is represented by a single row and each time-varying variable generates a different column for each time point. Tables 1 and 2 illustrate the long and wide arrangements for panel data. The tables display the data of variables $x, y$ and $z$ observed at 4 time points for the units 1 , 2 , and 3000 of the data used in Illustration 1. Long and wide formats are two alternative representations of the same data (Tables 1 and 2 show the same numbers, but in different arrangements). 
Table 2. The Wide Format.

\begin{tabular}{|c|c|c|c|c|c|c|c|c|c|}
\hline \multirow[b]{3}{*}{ Unit } & \multicolumn{8}{|c|}{ Time-Varying } & \multirow{3}{*}{$\frac{\text { Time-Invariant }}{z}$} \\
\hline & \multicolumn{2}{|c|}{ Time I } & \multicolumn{2}{|c|}{ Time 2} & \multicolumn{2}{|c|}{ Time 3} & \multicolumn{2}{|c|}{ Time 4} & \\
\hline & $x_{1}$ & $y_{1}$ & $x_{2}$ & $y_{2}$ & $x_{3}$ & $y_{3}$ & $x_{4}$ & $y_{4}$ & \\
\hline I & -0.34 & -4.53 & -0.85 & -1.96 & 0.05 & -2.17 & 1.48 & 3.65 & -1.42 \\
\hline 2 & -0.85 & 0.42 & 0.61 & 3.41 & 0.06 & 4.39 & 0.83 & 6.86 & 0.22 \\
\hline 3000 & 1.00 & 1.79 & 0.06 & 1.27 & 0.25 & 3.14 & -0.64 & -3.42 & 0.82 \\
\hline
\end{tabular}

Software routines are available to convert wide format data to long format, and vice versa (in Stata and R, the command reshape).

In the long format, increasing $T$ increases the number of rows but not the number of columns. In the wide format, increasing $T$ increases the number of columns but not the number of rows. An advantage of the wide format is that it allows the researcher more flexible specifications of the temporal interdependence in the model. However, in some research contexts, such as when dealing with a large number of time points, and/or the timing of the measurement occasions varies across units, the wide format may be impractical because of the considerable increase in the number of columns (Singer \& Willett, 2003, p. 21). It should also be mentioned that some temporal interdependencies, such as an autoregressive error term, can also be specified in the long format data (see, for example, Rabe-Hesketh \& Skrondal, 2012, chap. 6).

An essential feature of the long format for panel data is the likely association (statistical dependence) among rows that belong to the same unit (e.g., the same firm). Therefore, the long format panel data are likely to produce what is called positive intraclass correlation (ICC), which is the proportion of total variance of a variable that can be explained by group (unit) membership. One estimate of ICC is the ICC(1) (Bliese, 2000, pp. 354-355). ${ }^{2}$ Positive values of the ICC(1) indicate that, on average, scores of rows belonging to the same group are more similar than scores between groups (Kenny \& Judd, 1986). In the wide format, however, since different rows correspond to the different units, they are assumed to be independent, and ICC(1) manifests as a correlation between the variables that store the different time observations.

These two formats give rise to the two approaches to panel data discussed in this article: univariate for the long format data; multivariate for the wide format. The basic models for these two approaches are discussed next.

\section{Models}

\section{Univariate Approach}

The basic model for the univariate approach is the following regression equation: ${ }^{3}$

$$
y_{i t}=\alpha+\beta x_{i t}+\gamma z_{i}+u_{i}+\varepsilon_{i t},
$$

where, for unit $i$ at time $t, y_{i t}, x_{i t}$ and $z_{i}$ are the values of the dependent variable $y$ and the independent variables $x$ and $z$, respectively; $\beta$ and $\gamma$ are the regression coefficients; $\alpha$ is a constant intercept; $u_{i}$ is a centered unobserved variable varying only with the unit $i$, with variance $\sigma_{u}^{2}$; and $\varepsilon_{i t}$ is an equation disturbance term (that varies with unit and time), centered, with variance $\sigma_{\varepsilon}^{2}$, and independent of $x, z$ and $u_{i}$. Considering $\alpha_{i} \equiv \alpha+u_{i}$, equation (1) can be viewed as a regression equation with an intercept $\alpha_{i}$ that varies with the unit $i$. Even though equation (1) is a multiple regression model, it 
is univariate in nature since it expresses the variation of a single variable, the dependent variable $y$, conditional to the values of independent variables.

The varying $u_{i}$ represents the combined effect on $y$ of all unobserved unit-specific characteristics that are constant (or fixed) over time (Halaby, 2004). In empirical applications it is reasonable to assume that units are heterogeneous with respect to these unobserved characteristics. Suppressing the term $u_{i}$ in equation (1) is equivalent to merging $u_{i}$ with the disturbance term $\varepsilon_{i t}{ }^{4}$ In this case, when $u_{i}$ correlates with the independent variables $x$ and $z$, we have what is called "omitted variable bias" (Antonakis et al., 2010) and the OLS estimates of $\beta$ and $\gamma$ fail to be consistent (an estimator is said to be consistent when it converges to the true value when sample size increases, and this is the basic criterion for an estimator to be considered useful).

The traditional econometrics of panel data (see, e.g., Wooldridge, 2013, chap. 14) use two type of estimators for the parameters in equation (1), the so-called "fixed effect" (FE) and "random effect" (RE). Before discussing these estimators, it is useful to clarify the terms "fixed" and "random" as used in mixed-effect regression (or hierarchical linear models, HLM) versus their use in the econometric literature on panel data. In mixed-effects regression (and HLM), a parameter is said to be "fixed" when it remains constant at all levels of the hierarchy, for example, the $\beta$ and $\gamma$ of our model; it is said to be "random" when it varies at a certain level of the hierarchy, for example, the intercept $\alpha_{i} \equiv \alpha+u_{i}$ that varies with the units. In the econometric literature, however, FE and RE simply denote two type of estimators of $\beta$ in a model where $\alpha_{i}$ varies across units; so, in both cases, using mixed-effects regression terminology, the intercept is not a fixed parameter! In the present article, we assume $\alpha_{i}$ is an unobserved random variable varying across units. Two different models will emerge depending on whether $\alpha_{i}$ is allowed to correlate or not (at unit level) with the time varying variables. ${ }^{5}$

\section{The Fixed-Effect (FE) Estimator}

Under the presence of the varying intercept $\alpha_{i}$, one simple procedure to estimate the regression coefficient $\beta$ of (1) consists in eliminating the between-unit variation and then applying OLS to the resulting within-unit variation. The specification (1) implies the between-unit regression

$$
\overline{y_{i}}=\alpha+\beta \overline{x_{i}}+\gamma z_{i}+u_{i}+\overline{\varepsilon_{i}}
$$

where the bar over a symbol denotes a cluster mean; thus, subtracting (2) from (1) gives

$$
y_{i t}^{*}=\beta_{k} x_{i t}^{*}+\varepsilon_{i t}^{*}
$$

where $y_{i t}^{*}=\left(y_{i t}-\bar{y}_{i}\right), x_{i t}^{*}=\left(x_{i t}-\bar{x}_{i}\right)$ and $\varepsilon_{i t}^{*}=\left(\varepsilon_{i t}-\bar{\varepsilon}_{i}\right)$. The transformed regression (3) has the same regression coefficient $\beta$ as in (1) and is free of the problem of a varying intercept. The OLS estimator of $\beta$ in (3) is known as the fixed effects (FE) estimator (also known as the within estimator). ${ }^{6}$ Adjustment for the degrees of freedom consumed by computing the averages is required in the OLS formulas for standard errors and test statistics (see Wooldridge, 2013, p. 484). Statistical software such as Stata (Stata Corp., 2015), for example, uses the xtreg command with the option $\mathrm{fe}$ to produce the FE estimator. One important property of the FE is that it is a consistent estimator of $\beta$ (Allison, 2009, p. 7). Simple differentiation of the data has removed all possible influences of the (stable) unit characteristics on the dependent variable, rendering $x^{*}$ exogenous with respect to $\varepsilon_{i t}^{*}$ (Antonakis et al., 2010).

There are however some disadvantages in the FE estimator. First, it does not provide estimators for $\gamma$, since the time-invariant variable $z$ has been eliminated from the equation (Antonakis et al., 2010). Second, as the between-unit variation has been eliminated by the transformation, there is a loss of efficiency (i.e., precision of the estimates), thus decreasing the likelihood of detecting a significant effect (Bliese \& Ployhart, 2002), unless the within-unit variation dominates in the analysis. Finally, as in any regression analysis, consistency of the FE estimator of $\beta$ requires the 
correct specification of the regression equation (with no omitted variables, lack of interaction terms, etc.) and - this is essential in our panel data setup - having invariance across time of all the regression parameters. Violation of the latter assumption is exemplified in Illustration 1 below.

\section{Random-Effect (RE) Estimator}

An alternative approach to estimate (1) is to assume the $\alpha_{i}$ s are realizations of a random variable of mean $\alpha$ and variance $\sigma_{u}^{2}$ independent of the variables $x$ and $z$. This is a particular case of the so-called mixed-effects regression where $\beta$ and $\gamma$ are fixed parameters and the intercept $\alpha_{i}$ is a random parameter. Mixed-effects regression models have a long tradition in biometrics; estimation methods have been developed based on maximum likelihood (ML) or iterative generalized least squares (Croissant \& Millo, 2008; Laird \& Ware, 1982).

Despite the fact that $\beta$ and $\gamma$ are fixed parameters (the only random parameter is $\alpha_{i}$ ), in econometrics the estimates of $\beta$ and $\gamma$ arising from mixed-effect regression are denoted "random effects" (RE) estimators. The xtreg command in Stata uses two implementations of an RE estimator: the feasible generalized least squares (GLS) estimator with quasi-groups mean centered data, based on estimated variance components, ${ }^{7}$ and the ML estimator of a random intercept model. These estimators are produced with the options $r e$ and mle respectively. ${ }^{8}$ In what follows, by (univariate) RE estimator we mean the latter estimator. This is the estimator that will be compared to a (multivariate) $\mathrm{RE}$ estimator discussed in the section on the multivariate approach.

When the random intercept $\alpha_{i}$ is independent of $x$ and $z$, the RE estimator is consistent for $\beta$ and $\gamma$, and the RE estimator of $\beta$ is more efficient (i.e., it has smaller variance) than the FE estimator. The efficiency gain of the RE increases with the increase of the between-unit variation (Halaby, 2004, p. 520). A problem with the RE estimator, however, is that it may suffer from bias (i.e., its expected value deviates from the true value) when $\alpha_{i}$ correlates with the independent variables (Antonakis et al., 2010); in that case, the FE estimator would be preferred since it provides a consistent estimator for $\beta$. The FE estimator of $\beta$ (and its corresponding standard error) can also be obtained when the RE estimator is applied to a model where the cluster mean $\bar{x}_{i}$ has been added as an independent variable (Mundlak, 1978); this is called the correlated random effect approach (see Wooldridge, 2013, sec. 14.3). ${ }^{9}$

\section{Multivariate Approach}

The alternative to the univariate approach of (1) is the following set of $T$ simultaneous regression equations:

$$
y_{i t}=\alpha_{t}+\beta_{t} x_{i t}+\gamma_{t} z_{i}+u_{i}+\varepsilon_{i t}, \quad t=1, \ldots, T,
$$

where the variables $x_{i t}, z_{i}, u_{i}$ and $\varepsilon_{i t}$ are the same as in equation (1), and $\alpha_{t}, \beta_{t}$ and $\gamma_{t}$ are the parameters $\alpha, \beta$ and $\gamma$ of equation (1), now possibly varying with t. The disturbance term $\varepsilon_{i t}$ has variance $\sigma_{\varepsilon}^{2}(t)$, allowed to be heteroscedastic (varying with $t$ ) and, unless explicitly stated otherwise, it is assumed to be uncorrelated across time. Note that the equivalent to the random intercept $\alpha_{i}$ of equation (1) is $\alpha_{i t} \equiv \alpha_{t}+u_{i}$, whose mean $\alpha_{t}$ now possibly varies with t.

Time-varying coefficients could be reproduced in the univariate approach by introducing time-dummy variables and their interactions with the $x$ s (see Allison, 2009, p. 19), as well as heteroscedasticity and autocorrelated error terms (see Rabe-Hesketh \& Skrondal, 2012, chaps. 3-6; Snijders \& Bosker, 2012, chap. 12). ${ }^{10}$ In the illustration sections we will comment further on the univariate approach with time varying parameters.

To complete the specification, we need to introduce the parameters of covariances among $x_{1}, \ldots, x_{T}, z, u_{i}$. It is assumed that $u_{i}$ is uncorrelated with the time-invariant variables (the $z \mathrm{~s}$ ). This assumption of zero correlation is needed to have an identified model (a free correlation would 


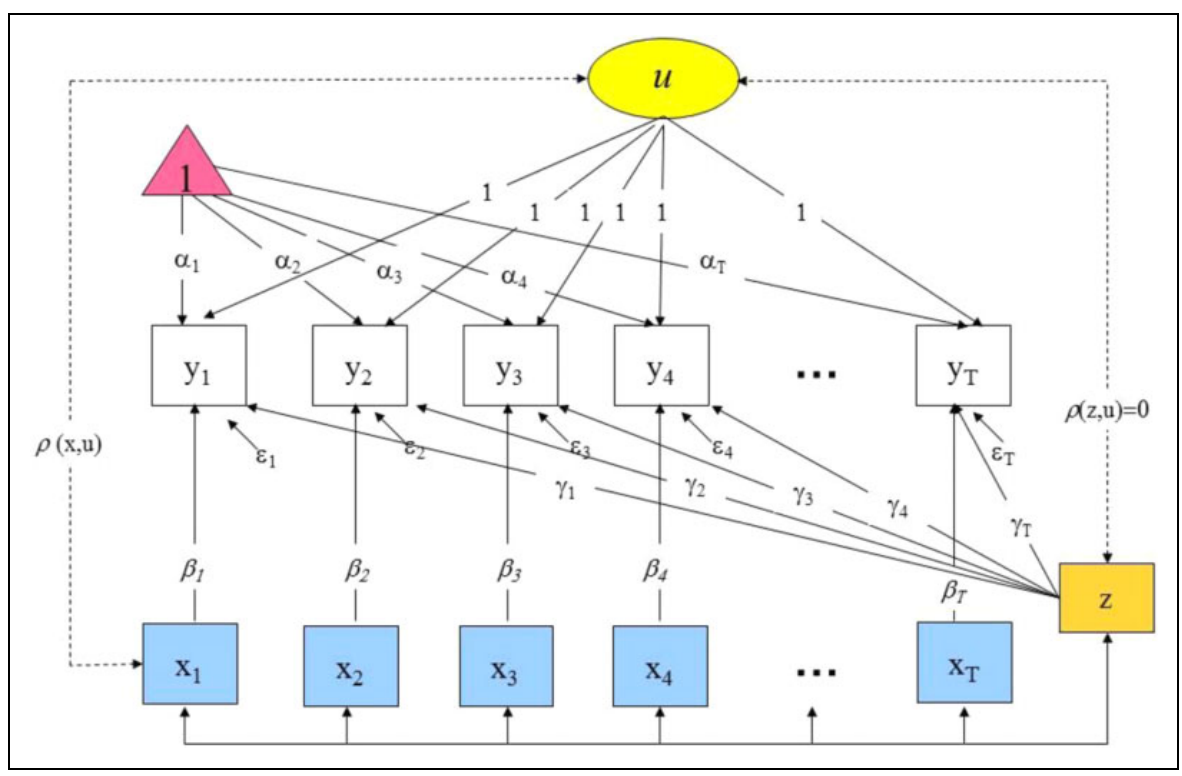

Figure I. Path model representation of the multivariate specification (5).

confound $u_{i}$ with $z$ ), though equivalent models (Bentler \& Satorra, 2010) are obtained when fixing the covariance between $u_{i}$ and $z$ to any arbitrary value. An even more general multivariate model than (5) could be specified. For example, Bollen and Brand (2010) propose a model specification that replaces $u_{i}$ with $\lambda_{t} u_{i}$ where the $\lambda_{t}$ accounts for heterogeneity across time of the random intercept's impact on the dependent variables. As in regular factor analysis, one $\lambda_{t}$ needs to be set to 1 for identification of the model. When $x$ and $z$ are absent from the model, then (5) is simply a "confirmatory" single-factor model (Jöreskog, 1969).

As noted already in Bollen and Brand (2010), the specification (5) is a particular structural equation model. A useful language to represent an SEM is the path diagram. Figure 1 shows the path diagram representation of (5). The unobserved unit effect is represented by the variable $u_{i}$ in the circle. The variables in the squares are the time-varying variables $y$ and $x$ and the time-invariant $z$. Arrows in the figure correspond to regression coefficients, and double-headed arrows (both solid and dashed) correspond to covariances among variables. The path diagram has set free the correlations among the unobserved $u$ and the time-varying independent variables $x \mathrm{~s}$, denoted in the path model by $\rho(x, u)$, with the correlation between $u$ and $z$ set to zero. Disturbance terms are represented by the $\varepsilon_{t} \mathrm{~s}$ with single-headed arrows pointing to $y_{t} \mathrm{~s}$. Finally, the triangle is the constant to 1 and serves to represent the intercepts of the equations (arrows emanating from the constant to 1 correspond to the $\left.\alpha_{t} \mathrm{~s}\right)$. Figure 1 shows that the loadings of $u$ to $y \mathrm{~s}$ are set to 1 .

Maximum likelihood (ML) estimation (and weighted least squares, for different weight matrices) of (5), can routinely be obtained using regular software for SEM analyses, such as EQS (Bentler, 2006), Mplus (Muthén \& Muthén, 1998-2012), LISREL (Jöreskog \& Sörbom, 2006), sem in Stata, the lavaan package of R (Rosseel, 2012), and others. Nowadays, these software packages also offer the option of ML analysis with missing data (Arbuckle, 1996), which can deal with MAR-type informative missingness (Rubin, 1976; we use this estimation method in Illustration 2 to cope with unbalance in the panel and missing values, as will be clarified below). See Bollen (1989) for a general overview of SEM methods; and, for example, Satorra and Bentler $(1990,1994)$ for technical 
details of estimation, model testing and model modification in SEM under general conditions on the distribution of the data.

\section{A Restricted Multivariate Panel Data Model}

A more restricted specification of (5) is when we impose the following TI assumption:

Time Invariance (TI): Invariance across time of the intercept, regression parameters and variance of the disturbance terms: $\alpha_{t}=\alpha, \beta_{t}=\beta, \gamma_{t}=\gamma, \sigma_{\varepsilon}^{2}(t)=\sigma_{\varepsilon}^{2}$.

Bollen and Brand (2010; see also Ejrnaes \& Holm, 2006; Teachman et al., 2001) argue that the TI assumption and the specification of the correlation between $u_{i}$ and the independent variables $x$ correlation set free, or restricted to be zero-make FE and RE estimates of parameters obtained under specifications (1) and (5) (asymptotically) equal. Illustration 1 below explores this equivalence in the context of a specific data set.

In some research scenarios, the restrictions imposed by the TI assumption may be questionable, such as when the effect of an independent variable on the dependent variable increases (or decreases) over time. For instance, in the organizational research context it is plausible that the impact of yearly R\&D investments on firm profitability differs for recession and expansion periods; or that the impact of advertising investments decreases as the message filters through to current customers. Similarly, homoscedastic error terms is not a suitable assumption when the dependent variable tends to become either more or less variable over time, as in the case, for example, of analyzing the performance of employees in a new job, which initially shows a high degree of variability but diminishes over time as their expertise grows (Bliese \& Ployhart, 2002), or in the study of firm profitability, whose variation may diminish over time when, as consequence of competitive pressures, less profitable firms exit the market. Therefore, the TI assumption is essential for the validity of inferences of the univariate approach to panel data. Violation of this assumption can introduce severe bias in the FE and RE parameter estimates. Tools for assessing the validity of the restrictions are important in practice and will be further discussed below.

\section{Multivariate FE and RE Estimates}

The TI assumption does not fully determine the equivalence between estimates derived from the univariate and multivariate approaches. We also need to specify the free or restricted nature of the covariances between $u$ and the independent variables $x$ s (recall that the covariance of $u$ with the $z \mathrm{~s}$ have already been set to zero). In the multivariate specification (5) we distinguish two cases:

(A): covariances of $u$ with each $x_{1}, \ldots, x_{T}$ set free

(B): covariances of $u$ with each $x_{1}, \ldots, x_{T}$ set to zero

Illustration 1 below (which uses demonstration balanced panel data) will show that the multivariate approach under hypotheses (A) or (B) exactly matches the (univariate) FE estimate of $\beta$, or the (univariate) RE estimate of $\beta$ and $\gamma$, respectively. This exact match also applies to the corresponding standard error. ${ }^{11}$ So inferences are asymptotically equivalent for the univariate and multivariate approaches for FE and RE estimates. In the present article, multivariate FE and RE estimates refer to the estimates obtained under the specification (5), conditions (A) and (B), respectively, and the TI assumption. A path diagram representation of both options is obtained when all the parameters in Figure 1 are set time-invariant and the covariance parameters $\rho(x, u)$ are set free (FE) or restricted to zero (RE).

Since the specification (B) is nested within (A), a SEM chi-square difference test for the two models should serve the same purpose as the classic Hausman test (Hausman, 1978) common in the univariate approach (Allison \& Bollen, 1997; Bollen \& Brand, 2010; Teachman et al., 2001). 


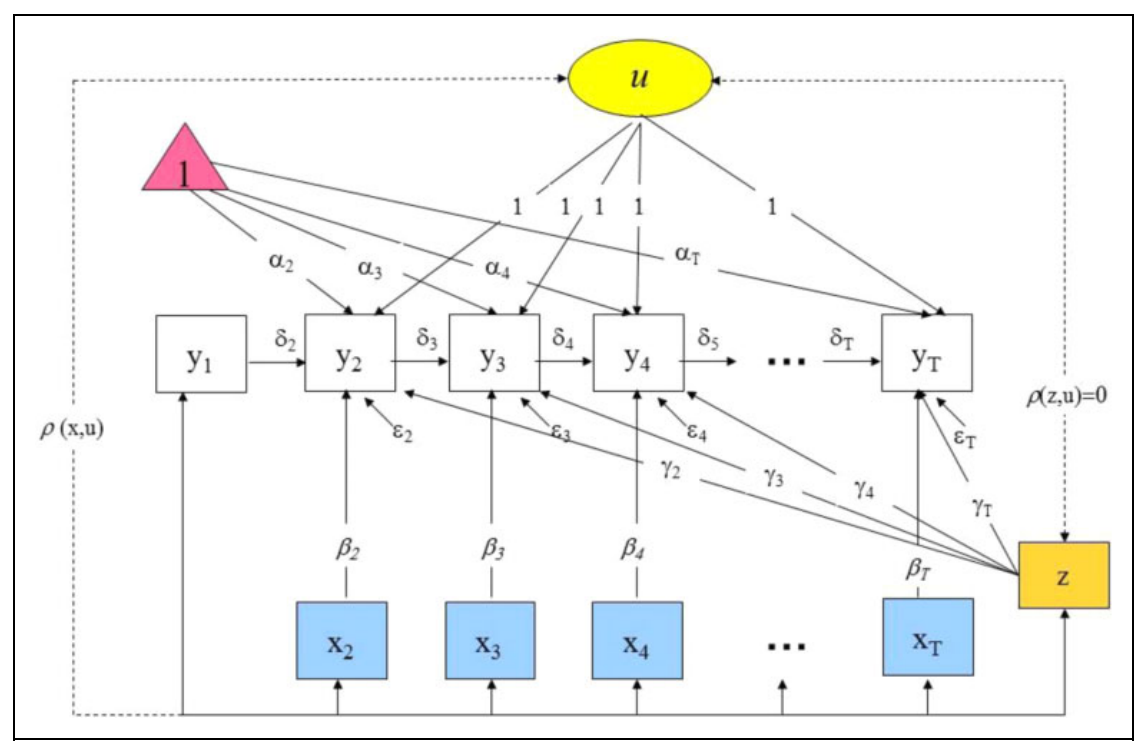

Figure 2. General multivariate model for dynamic panel data.

A significant value of the test statistics will reject using the RE estimator (assumption B) in favor of the FE estimator (assumption A).

Both specifications (A) and (B) imply SEMs with a large number of overidentifying restrictions that may induce model misfit, not only the time-invariance constraints implied by TI, but the lack of dynamic components of the model (i.e., serial correlated disturbances, lagged dependent variables, etc.). The path diagram of Figure 1 clearly shows the missing paths between variables across different years; in SEM, these missing paths correspond to parameters that are set to zero.

\section{Dynamic Panel Data Models}

The multivariate specification (5) can be expanded very simply to the so-called dynamic panel data models where the lagged variable $y_{t-1}$ is included in the regression equation. The model is expressed as the following set of $T-1$ simultaneous equations:

$$
y_{i t}=\alpha_{t}+\beta_{t} x_{i t}+\gamma_{t} z_{i}+\delta_{t} y_{i t-1}+u_{i}+\varepsilon_{i t}, \quad t=2, \ldots, T,
$$

where, as in the previous multivariate model (5), we allow time-varying parameters and covariances among the varying intercept and the time-varying variables $x$ s and $y$ at time 1 . The corresponding path diagram representation of this model is shown in Figure 2. Note the one-way arrows connecting the $y \mathrm{~s}$ (dynamics in the model), and that one wave of data is lost in the analysis. A formal presentation of this model and the assumptions for estimating it can be found in Bollen and Brand (2010). This specification is a SEM that can be estimated using standard software.

This multivariate formulation considerably expands the type of dynamic panel models accessible to practitioners. Estimating models with autoregressive errors is often recommended in the univariate perspective (Bliese \& Ployhart, 2002; Short, Ketchen, Bennett, \& Du Toit, 2006). Halaby (2004) makes, however, a distinction between the dynamics introduced as an autoregressive structure on the $y \mathrm{~s}$, or simply as correlation among error terms. We could also have measurement error on the dependent variable, lagged effects of independent variables, multiple indicators, and so on. These models can be easily estimated in the same SEM setup. See Finkel (1995, chap. 5) for more examples of dynamic panel data models expressed in the multivariate approach, and Bou and Satorra 
$(2007,2009,2010)$ for specific analyses of dynamic panel data models with measurement error in different data settings (multiple-group, hierarchical data, and finite mixtures).

The univariate approach also deals with dynamic panel data models; the presence, however, of both a varying intercept and lagged dependent variables pose endogeneity problems that go beyond the methods described above for the FE and RE estimates (Antonakis et al., 2010). A great deal of econometric research has been devoted to dynamic panel data models. Estimation methods based on instrumental variables have been developed following Anderson and Hsiao (1982) with estimators differing on the transformation of the data used and the choice of instruments (see Arellano, 2003, chaps. 5-7, for full details of these methods).

\section{Other Extensions of the Multivariate Approach}

A variety of related models can be proposed in the multivariate framework, depending whether the model includes time-varying independent variables or not, and whether the independent variables are observable or latent. For example, the classic first-order autoregressive model (Kessler \& Greenberg, 1981, chap. 7) can be specified as a special case of the dynamic multivariate model in equation (6) in which the independent variables are not included in the model. Similarly, other dynamic models allowing lagged values of both the dependent and independent variables and reciprocal effects, such as the cross-lagged model, have been estimated in the same multivariate framework (see Allison, 2009, chap. 6). These models, framed within the tradition of the analysis of interindividual differences (Baltes \& Nesselroade, 1979), provide a better understanding of the relationships between repeatedly measured variables (and constructs) over time.

Other well-established panel data models used in repeated-measures designs to study intraindividual differences over time can be fitted using the multivariate panel data approach. This is the case of univariate and multivariate repeated-measures ANOVA (Misangyi et al., 2006; O'Brien \& Kaiser, 1985) used for testing changes (i.e., growth) in means over time (Bergh, 1995), and LGC models (T. E. Duncan \& Duncan, 1995; McArdle \& Epstein, 1987; Meredith \& Tisak, 1990; Rogosa \& Willett, 1985) that allow change trajectories that vary across individuals. In particular, a standard LGC model (i.e., with no independent variables) can be specified by adding to the multivariate model in Figure 1 a second latent variable with time varying loadings (the random slope component) that accounts for unit-specific variation across time of the mean of $y$. The loadings of the random slope variable can be specified as either fixed values (defining linear or polynomial growth trajectories), or free parameters to empirically define the functional form of the changes in the mean of $y .{ }^{12}$ Similarly, repeated-measures ANOVA can be considered as a particular case of the LGC model where the random slopes are not allowed to vary across individuals (i.e., setting to zero the variance and the covariances of the random slope latent variable; McArdle, 2012).

\section{Illustration I: Demonstration Data}

To aid the comparison of the univariate and multivariate approaches, we first present an illustration with demonstration - i.e., artificial - data. This involves one-sample panel data with certainty on the model and population values of the parameters. This type of data allows estimates to be compared with each other and with respect to the true values, and uncovers the impact of misspecification on the values of various test statistics. For simplicity, only three variables, the $y, x$ and $z$, and four time points are considered. The data was produced by equation (5) with the polulation values of parameters shown in Table 3. Note that the regression coefficient $\beta$ is not constant across time. This violation of the TI assumption will allow model misspecification to be illustrated. A reasonably large sample, $N=3000$, was chosen to avoid cluttering with small sample size artifacts. The Stata syntax and seed number that 
Table 3. Population Values and SEM Analysis: Demonstration Data.

\begin{tabular}{|c|c|c|c|c|}
\hline & Population Value & Estimate & SE & $95 \% \mathrm{Cl}$ \\
\hline \multicolumn{5}{|l|}{$t=\mathrm{I}:$} \\
\hline$x$ & 2.000 & 2.002 & 0.023 & {$[1.945,2.036]$} \\
\hline$z$ & 3.000 & 2.996 & 0.021 & {$[2.935,3.042]$} \\
\hline$\alpha$ & 0.000 & 0.987 & 0.019 & {$[-0.0258,0.046]$} \\
\hline$\sigma_{\varepsilon}^{2}$ & 1.000 & 1.016 & 0.028 & {$[0.960,1.069]$} \\
\hline \multicolumn{5}{|l|}{$t=2$} \\
\hline$x$ & 0.000 & 0.050 & 0.037 & {$[-0.022,0.122]$} \\
\hline$z$ & 3.000 & 2.938 & 0.035 & {$[2.869,3.006]$} \\
\hline$\alpha$ & 0.000 & 0.954 & 0.018 & {$[0.918,0.991]$} \\
\hline$\sigma_{\varepsilon}^{2}$ & 1.000 & 0.979 & 0.027 & {$[0.928,1.034]$} \\
\hline \multicolumn{5}{|l|}{$t=3:$} \\
\hline$x$ & 2.000 & 2.022 & 0.022 & {$[1.978,2.066]$} \\
\hline$z$ & 3.000 & 3.021 & 0.019 & {$[2.983,3.058]$} \\
\hline$\alpha$ & 0.000 & 0.996 & 0.018 & {$[0.960,1.032]$} \\
\hline$\sigma_{\varepsilon}^{2}$ & 1.000 & 0.996 & 0.018 & {$[0.960,1.032]$} \\
\hline \multicolumn{5}{|l|}{$t=4$} \\
\hline$x$ & 4.000 & 4.020 & 0.021 & {$[3.978,4.062]$} \\
\hline$z$ & 3.000 & 2.969 & 0.018 & {$[2.933,3.005]$} \\
\hline$\alpha$ & 0.000 & 0.978 & 0.018 & {$[0.943,1.014]$} \\
\hline$\sigma_{\varepsilon}^{2}$ & 1.000 & 0.948 & 0.026 & {$[0.898,1.001]$} \\
\hline$\sigma_{u}^{2}$ & 1.000 & 0.962 & 0.025 & {$[0.914,1.012]$} \\
\hline $\operatorname{cov}\left(u_{i}, x_{l}\right)$ & 0.1 & 0.131 & 0.011 & {$[0.110,0.152]$} \\
\hline $\operatorname{cov}\left(u_{i}, x_{2}\right)$ & 0.5 & 0.472 & 0.007 & {$[0.458,0.486]$} \\
\hline $\operatorname{cov}\left(u_{i}, x_{3}\right)$ & 0.2 & 0.187 & 0.012 & {$[0.164,0.210$} \\
\hline $\operatorname{cov}\left(u_{i}, x_{4}\right)$ & 0.8 & 0.785 & 0.012 & {$[0.761,0.810]$} \\
\hline$\chi^{2}$ & & 14.65 & & \\
\hline$d f$ & & 13 & & \\
\hline$p$ value & & .33 & & \\
\hline
\end{tabular}

generates the one-sample data is shown in Appendix A. The code for all the univariate and multivariate analyses reported in this section is shown in Appendix A (code in Stata) and Appendix B (code in R).

Table 3 shows estimates, standard errors, and 95\% confidence intervals (CIs) for all the parameters of the true model (a model that do not impose the TI assumption). Since we are analyzing a (true) correct model, it is not surprising that the $95 \% \mathrm{CI}$ of each of the parameters contains its true population value. Furthermore, the chi-square goodness-of-fit test equals $14.65, d f=13, p=.33$; so, as expected, the model is not rejected by the test. Our intention, however, with this illustration is to see the estimates and test statistics when the model is misspecified.

\section{Comparison of Univariate and Multivariate Approaches}

Table 4 shows the estimation results (estimates, $S E$, and $\mathrm{CI}$ ) for the univariate (first panel) and multivariate (second panel) representations of FE (left-hand side of the table) and RE (right-hand side). The results were obtained with Stata: the univariate used xtreg, fe (for FE) and xtreg, mle, or mixed with $\mathrm{ml}$ (for RE); the multivariate used sem, estimation method ml. Identical numbers were obtained when using other SEM software such as EQS and Mplus. ${ }^{13}$ 
Table 4. Results for the Univariate and Multivariate Analyses (FE and RE): Demonstration Data.

\begin{tabular}{|c|c|c|c|c|c|c|}
\hline \multicolumn{7}{|c|}{ Univariate } \\
\hline & \multicolumn{3}{|c|}{ FE } & \multicolumn{3}{|c|}{ RE } \\
\hline & Coef. & SE & $95 \% \mathrm{Cl}$ & Coef. & $S E$ & $95 \% \mathrm{Cl}$ \\
\hline$x$ & 2.079 & 0.023 & {$[2.034,2.124]$} & 2.503 & 0.022 & {$[2.46 \mathrm{I}, 2.545]$} \\
\hline $\mathrm{z}$ & - & & & 2.415 & 0.022 & {$[2.37 \mathrm{I}, 2.459]$} \\
\hline$\alpha$ & 0.999 & 0.016 & {$[0.967,1.031]$} & 0.973 & 0.021 & {$[0.932,1.014]$} \\
\hline$\sigma_{\alpha}^{2}$ & 8.082 & & & 0.489 & 0.040 & {$[0.417,0.574]$} \\
\hline$\sigma_{\varepsilon}^{2}$ & 3.160 & & & 3.278 & 0.050 & {$[3.181,3.378]$} \\
\hline \multicolumn{7}{|c|}{ Multivariate } \\
\hline & \multicolumn{3}{|c|}{$\mathrm{FE}$} & \multicolumn{3}{|c|}{ RE } \\
\hline & \multicolumn{3}{|c|}{$\rho(X, \eta) \neq 0$} & \multicolumn{3}{|c|}{$\rho(X, \eta)=0, \rho(Z, \eta)=0$} \\
\hline & Coef. & SE & $95 \% \mathrm{Cl}$ & Coef. & $S E$ & $95 \% \mathrm{Cl}$ \\
\hline$x$ & 2.079 & 0.023 & {$[2.034,2.124]$} & 2.503 & 0.022 & {$[2.46 \mathrm{I}, 2.545]$} \\
\hline z & 2.563 & 0.013 & {$[2.538,2.588]$} & 2.415 & 0.022 & {$[2.371,2.459]$} \\
\hline$\alpha$ & 0.999 & 0.010 & {$[0.979,1.018]$} & 0.973 & 0.021 & {$[0.932,1.014]$} \\
\hline$\sigma_{u}^{2}$ & 0.870 & 0.035 & {$[0.803,0.94 I]$} & 0.489 & 0.040 & {$[0.417,0.574]$} \\
\hline$\sigma_{\varepsilon}^{2}$ & 3.160 & 0.047 & {$[3.069,3.253]$} & 3.278 & 0.050 & {$[3.181,3.378]$} \\
\hline$\chi^{\frac{\varepsilon}{2}}$ & 10531.35 & & & $|5436.4|$ & & \\
\hline$d f$ & 25 & & & 29 & & \\
\hline$p$ & .00 & & & .00 & & \\
\hline
\end{tabular}

We first discuss the results for FE estimates. The univariate and multivariate FE estimates of $\beta$ are identical, with the same standard error, in the three decimal places reported. The multivariate FE also produces an estimator (and standard error) for $\gamma$, the regression coefficient of $z$, which was not available in the univariate FE. An estimate of $\gamma$, however, could also have been obtained by using the correlated random effect approach discussed in the RE estimator section; in our data, this estimate is $2.101(S E=0.021)$, a value that departs from the multivariate FE estimate reported in the table. We note equality of the univariate and multivariate $\mathrm{FE}$ estimates of $\sigma_{\varepsilon}^{2}$; the multivariate $\mathrm{FE}$ also providing a standard error that could be useful to assess the significance of this variance. There is identity between the univariate and multivariate FE estimates of the mean of the random intercept $\alpha .{ }^{14}$ Note, however, there is no equality among the univariate and multivariate FE estimates of the variance $\sigma_{u}^{2}$ of the varying intercept. This deviation should be expected, since they are two different types of estimates: in the univariate FE, the estimate of $\sigma_{u}^{2}$ is a between variance computed from the "observed" residuals (thus it has no standard error); in multivariate FE, the value for $\sigma_{u}^{2}$ is a regular ML estimation (thus equipped with standard error); the $95 \%$ CI for $\sigma_{u}^{2}$, obtained with multivariate $\mathrm{FE}$, is a useful tool for assessing the presence of panel effects in the data. In the univariate approach, alternative tests for the presence of a significant variance of $\alpha_{i}$ are the Breusch and Pagan (1980) test, if the model is estimated using the GLS estimator, or a likelihood-ratio test if the model is estimated with ML (see Antonakis et al., 2010, p. 1093). Finally, the multivariate approach provides a chisquare goodness-of-fit test for the model, the $\chi^{2}=10531.35(d f=25, p=.00)$, which indicates (strong!) rejection of the model. This warning of model misspecification is absent in the univariate FE. While there is no equivalent overall test in the univariate approach, several diagnostics of 
possible model misspecification can be applied in the postestimation stage, as discussed in the following subsection.

For the multivariate RE, we now observe equality of estimates (and the same standard error) for all the parameters of the model: all regression coefficients, mean and variance of the varying intercept, and the variance of the disturbance term. Here also, the multivariate RE provides a chisquare goodness-of-fit test for the model: $\chi^{2}=15436.41(d f=29, p=.00)$, an indication that the model is rejected. Note that RE increases by 4 the $\mathrm{df}$ of FE; this corresponds to 4 zero constraints (the correlations of $u_{i}$ with $x_{1}, x_{2}, x_{3}$, and $x_{4}$ ) added to the model (option (B) of the subsection "Multivariate FE and RE Estimates").

Comparing the population values of parameters (see second column of Table 3 ) with the $95 \% \mathrm{CI}$ of the multivariate FE and RE estimates, we see that none of the population values is covered by the $\mathrm{CI}$, in clear contrast to the results shown in Table 3 when a true model was used. We know TI does not hold in our data, since the population values of $\beta$ are 2, 0,2 and 4 for $t=1,2,3,4$. The models underlying the $\mathrm{FE}$ and RE estimates force all the parameters to be equal, obtaining a common estimate for $\beta$ equal to $2.079(S E=0.023)$ in the case of $\mathrm{FE}$, and $2.503(S E=0.022)$ in the case of RE, both numbers biased with respect to the true values. Note that bias is also observed for the estimates of $\gamma$, a parameter that is correctly restricted invariant across time, but whose population value also falls outside the $95 \%$ CI of the FE and RE estimate for both univariate and multivariate approaches. We see that misspecification of the model, attested by the chi-square goodness-of-fit test, may substantially deteriorate the quality of estimates. Thus, prior to attempting substantive interpretation of results, a model diagnostic is desirable. Misfit and model modification for the models underlying FE and RE estimates are discussed next.

\section{Diagnostics for Model Modification}

The chi-square goodness-of-fit test shown in the multivariate approach (both for FE and RE) alerts the researcher to problems of misspecification of the model, likely prompting her/him to search for its sources. In SEM, the "Modification Indices" (MI; Sörbom, 1989; these are Lagrange Multiplier test statistics) in combination with the "Expected Parameter Change" (EPC; Saris, Satorra, \& Sörbom, 1987) are commonly used to detect restrictions causing model misfit. Inspection of the MIs of the model for FE point clearly to the parameter $\beta$ at times 2 and 4 . The MI value for $\beta$ at $t=4$ was $\chi^{2}=6198.56(d f=1, p=.00), \mathrm{EPC}=1.937$ (i.e., an estimated shift of 1.937, from the current estimate 2.079, if the restriction were released) strongly suggests the need to relax the constraint of $\beta$ at $\mathrm{t}=4$ (note that the true value for $\beta$ is 4 ). A model that sets free all the $\beta$ s yields $\chi^{2}=27.54$ $(d f=22, p=.19)$; so, the model now fits the data. The chi-square difference of the two nested models $\left(\Delta \chi^{2}=10531.35-27.54=10503.81, d f=3, p=.00\right)$ is highly significant, indicating the need to release the time-invariance constraint on $\beta \mathrm{s}$.

The univariate approach provides $F$ or Wald tests for the overall significance of the regression coefficients (as well as tests of significance of individual parameters). However, these tests give no information on the validity of the TI assumption or other sources of misspecification. Even though the univariate approach lacks overall testing of goodness-of-fit, regression-based diagnostic tools for misspecification could be applied to assess deviations from TI. An anonymous reviewer suggested using the added variable plot; Figure 3 shows this plot for the regression of $y$ on $x$ and $z$, with line fits for each time point added to the classic plot. This plot clearly shows the time-variation of the regression coefficient (slopes) for $x$ (when controlling for $z$ ), a pattern of variation coincident with the true one. Adaptation to panel data analysis of classic regression diagnostics tools is an interesting avenue that could supplement the results of the MIs and other tests with graphical information.

As mentioned above, regression coefficients that change over time can also be contemplated in the univariate approach. A model with time-varying $\beta$ (i.e., introducing interaction terms of $x$ with 


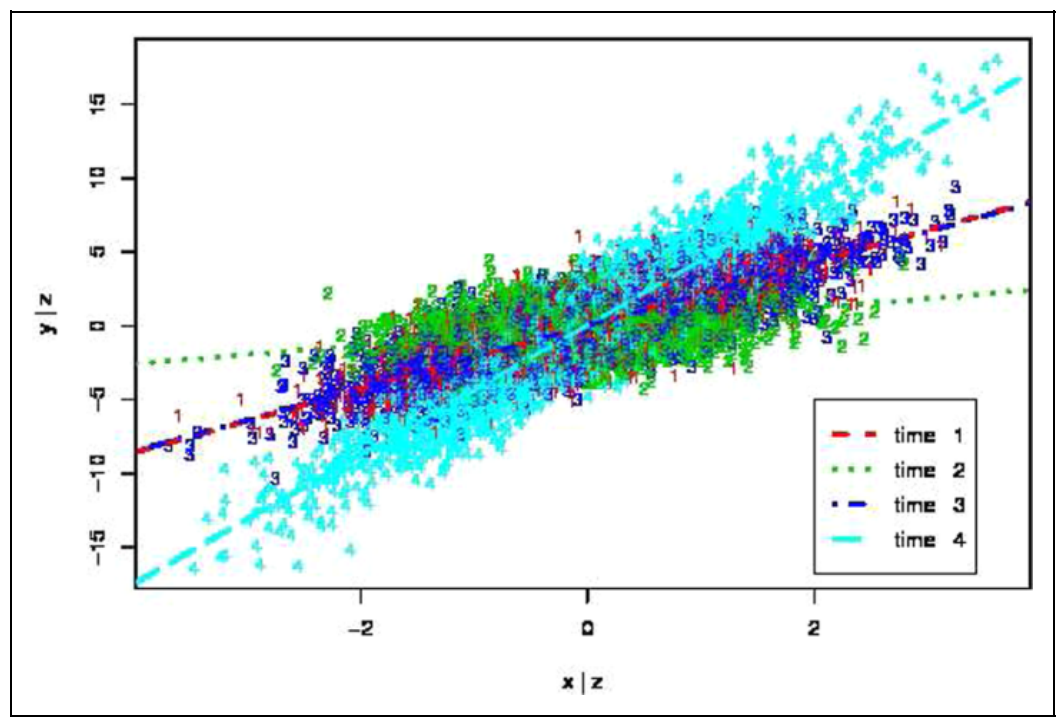

Figure 3. Added variable plot of model diagnostics in the univariate approach: Demonstration data.

the time-dummy variables) gives an estimate of $\beta$ of $2.003(S E=0.021)$, and the following estimates for the interaction terms (standard errors in parentheses): $-2.000(0.028), 0.022(0.028)$, and 2.013 (0.028) for time periods 2,3 , and 4 , respectively (the first time period is taken as a reference category). These values correctly reproduce the population values shown in Table 3.

\section{Illustration 2: Empirical Data}

We now compare the univariate and multivariate approaches in a real-data setup where we confront important practical issues such as missing data and uncertainty on the true model. The dependent variable $y$ is firms' profitability, the analysis aiming to specify a model that gives a reasonable description of the relation of profitability with firms' characteristics such as investment in R\&D, advertising, size, and so on. First, we briefly describe the variables and the panel.

\section{Variables}

The data come from the Encuesta Sobre Estrategias Empresariales (ESEE; Survey on Business Strategies), a survey carried out annually by the Spanish Ministry of Industry to collect information on Spanish manufacturing firms. The survey involves annual data for 10 consecutive years, 1993 to 2002, for a sample of $N=2,515$ firms.

The dependent variable $y$ is Return on Assets ( $\mathrm{r} \circ \mathrm{a}$; the ratio of annual net income to total assets), a measure of firm profitability widely used in organizational research (for exhaustive details on this variable, see, e.g., McGahan \& Porter, 1997; Rumelt, 1991; Schmalensee, 1985). The following time-varying independent variables $(x \mathrm{~s})$ are used: Capacity Utilization $(\mathrm{cu}$; ratio of the utilized productive capacity to the total installed capacity of the firm); $R \& D$ Intensity ( $r \& d$; the firms' annual R\&D expenditures divided by annual sales); Advertising Intensity (adv; ratio of the firms' total advertising expenses to sales); Size of the firm (s ize; log of number of employees). Just one time-invariant independent variable $(z)$ is included in the data analyzed: the year the firm was founded (Founding year, founded) taking 2002 as the reference year. Previous studies (e.g., Capon, Farley, \& Hoenig, 1990) found that these variables have a significant impact on firms' 
profitability. See also classic references that report a positive influence of independent variables on roa such as Aaker and Jacobson (1987), Farris and Reibstein (1979), Andras and Srinivasan (2003), Phillips, Chang, and Buzzell (1983), Kirner, Kinkel, and Jaeger (2009), Thornhill (2006), Brown and Eisenhardt (1995), Sinclair, Keppler, and Cohen (2000), and Buzzell, Gale, and Sultan (1975).

\section{Missing Data}

The data for this illustration deviate from the balanced panel data setup of Illustration 1, where every unit had complete information on all the variables for all time points. Panel data are said to be balanced when all the units are observed in all the time periods. In our data, only 560 firms ( $22 \%$ of the firms) have complete information for all the variables in all the years; that is, $78 \%$ of the firms have some form of missingness, either because they are not in the panel in some years (unbalanced panel), or because they miss one or more variables in some years (missing data); that is, in addition to deviation from a balanced panel, we still suffer from missingness in some variables. An important point in discussing consequences of missing data is the assumption of missing at random (MAR). This is the case when conditioning on the observed data the probability of missingness is unrelated with the value actually missed. See Rubin's (1976) seminal discussion on missing data. We address the analysis under MAR.

The simplest approach to missing data is listwise deletion: It discards any row of the data matrix that has an empty slot (i.e., a missing value in some of the columns). In our wide format data, applying listwise deletion leaves a data matrix with only 560 rows (the firms with complete data in all the years); that is, we lost $78 \%$ of the firms. In our long format data, we have 15,567 rows (firms by year with information in some of the variables), and listwise deletion leaves a data matrix with 13,980 rows (the remaining 1,587 rows have missing data in some variables in some years). So, in our data, the information retained with the listwise deletion varies for the wide and long format data sets. In the demonstration data of Illustration 1, where panel data was balanced with no missingness, this issue did not arise.

Fortunately, nearly all current software for SEM analysis now has the estimation option of $M L$ with missing data (Arbuckle, 1996; Graham, 2003). This estimator is invoked in sem of Stata by mlmv, the option to be used for the multivariate approach reported in the present illustration. This estimate ensures consistency under MAR and it retains and processes all the data of the initial 2,515 rows of the wide format data. In fact it uses more data than when applying listwise deletion to the long format data (the only option available in xtreg and mixed of Stata) that will necessarily discard the mentioned 1,587 rows that have missingness in some variables. It will be interesting the comparison of the results obtained from the univariate (listwise to long format data) and multivariate (ML for missing data) in this context of empirical data.

\section{Comparison of Univariate and Multivariate Approaches}

Table 5 shows the estimation results for the univariate (first panel) and multivariate (second panel) representations of the FE (left-hand side) and RE estimates (right-hand side). Estimates, standard errors, and $95 \%$ CIs are displayed in the table. All the numbers in this table were produced using Stata: in the univariate approach using xtreg, fe for FE, and xtreg, mle (or mixed with ml) for the RE; the multivariate approach using sem, estimation method mlmv.

We first discuss the results for FE estimates. The univariate and multivariate FE estimates of the regression coefficients for the time-varying variables (the $\beta$ s) are very similar, with also similar standard error (the largest difference on estimates occurs for $\beta$ of variable size, an estimate, however, that has a large standard error in both the univariate and multivariate approaches). The univariate and multivariate FE estimates of $\sigma_{\varepsilon}^{2}$ and the mean of the random 
Table 5. Results for the Univariate and Multivariate Analyses (FE and RE): Empirical Data.

\begin{tabular}{|c|c|c|c|c|c|c|}
\hline \multicolumn{7}{|c|}{ Univariate } \\
\hline & \multicolumn{3}{|c|}{$\mathrm{FE}$} & \multicolumn{3}{|c|}{$\mathrm{RE}$} \\
\hline & Coef. & $S E$ & $z$-value ${ }^{\dagger}$ & Coef. & $S E$ & $z$-value ${ }^{\dagger}$ \\
\hline $\mathrm{cu}$ & 0.072 & 0.009 & 8.08 & 0.078 & 0.008 & $|0.3|$ \\
\hline$r \& d$ & -0.290 & 0.063 & -4.64 & -0.243 & 0.051 & -4.73 \\
\hline$a d v$ & -0.356 & 0.074 & -4.80 & -0.033 & 0.048 & -0.68 \\
\hline size & -0.809 & 0.359 & -2.25 & -0.587 & 0.116 & -5.04 \\
\hline founded & - & - & - & -0.029 & 0.008 & $-3.5 I$ \\
\hline$\alpha$ & 7.250 & 1.654 & 4.38 & 6.075 & 0.763 & 7.96 \\
\hline$\sigma_{\alpha}^{2}$ & 78.194 & & & 34.378 & 1.663 & 20.67 \\
\hline$\sigma_{\varepsilon}^{2}$ & 84.670 & & & 86.527 & I. 143 & 75.70 \\
\hline \multicolumn{7}{|c|}{ Multivariate } \\
\hline & \multicolumn{3}{|c|}{$\mathrm{FE}$} & \multicolumn{3}{|c|}{ RE } \\
\hline & \multicolumn{3}{|c|}{$\rho(X, \eta)=$ free } & \multicolumn{3}{|c|}{$\rho(X, \eta)=0$} \\
\hline & Coef. & $S E$ & $z$-value ${ }^{\dagger}$ & Coef. & $S E$ & $z$-value ${ }^{\dagger}$ \\
\hline $\mathrm{cu}$ & 0.084 & 0.009 & 9.33 & 0.082 & 0.007 & 10.99 \\
\hline$r \& d$ & -0.268 & 0.062 & -4.30 & -0.215 & 0.049 & -4.36 \\
\hline $\mathrm{adv}$ & -0.361 & 0.075 & -4.80 & 0.016 & 0.046 & 0.34 \\
\hline size & -1.290 & 0.343 & -3.76 & -0.670 & 0.104 & -6.44 \\
\hline foundation & - & - & - & -0.029 & 0.007 & -3.86 \\
\hline$\alpha$ & 8.225 & 1.576 & 5.22 & 6.016 & 0.724 & 8.31 \\
\hline$\sigma_{u}^{2}$ & 40.250 & 2.272 & 17.48 & 36.377 & 1.732 & 21.00 \\
\hline$\sigma_{\varepsilon(t)}^{2}$ & 88.059 & 1.137 & 77.48 & 80.305 & I. 142 & 77.35 \\
\hline$\chi^{2}$ & $|658.8|$ & & & 1815.39 & & \\
\hline$d f$ & 427 & & & 467 & & \\
\hline$p$ & .00 & & & .00 & & \\
\hline
\end{tabular}

${ }^{\dagger}$ Ratio between estimate and SE.

intercept are also very similar. As was noted in the illustration with demonstration data, univariate and multivariate $\mathrm{FE}$ estimates of the variance of the varying intercept differ due to the estimators being based on different principles. The chi-square goodness-of-fit test $\chi^{2}=1,658.81$ $(d f=427, p=.00)$, pointed to rejection of the model, a warning that is not present in the univariate approach.

The univariate and multivariate RE results also show very close estimates and standard error, now for all the parameters of the model: regression coefficients, mean and variances of the varying intercept, and the variance of the disturbance term. Clearly, the z-values of the estimates lead to the same conclusion for the univariate and multivariate approaches. Now the chi-square goodnessof-fit test is $\chi^{2}=1,815.39(d f=467, p=.00)$, which also indicates rejection of the model. Note that the number of $d f$ of the RE estimator has increased by 40 , as we have restricted to zero the 40 parameters corresponding to the covariances of $u_{i}$ with the time-varying independent variables (4 variables times 10 years).

In addition, FE and RE estimates give nearly the same results except for the significance of the variable advertising adv, which is highly significant in the case of FE but nonsignificant in the case 
Table 6. A Sequence of Model Testing.

\begin{tabular}{llcr}
\hline Model & Model Restrictions (Within TI) & $\chi^{2}(\mathrm{df})$ & $\Delta \chi^{2}(\mathrm{df})$ \\
\hline M0: FE & $\alpha_{t}=\alpha ; \beta_{t}=\beta ; \gamma_{t}=\gamma ; \lambda_{t}=\lambda ; \sigma_{\varepsilon}^{2}(t)=\sigma_{\varepsilon}^{2}$ & $1658.805^{*}(427)$ & I56.58* (40) \\
MI: $\alpha_{t}=\alpha$ & $\beta_{t}=\beta ; \gamma_{t}=\gamma ; \lambda_{t}=\lambda ; \sigma_{\varepsilon}^{2}(t)=\sigma_{\varepsilon}^{2}$ & $1509.082^{*}(418)$ & $149.72^{*}(9)$ \\
M2: $\beta_{t}=\beta$ & $\gamma_{t}=\gamma ; \lambda_{t}=\lambda ; \sigma_{\varepsilon}^{2}(t)=\sigma_{\varepsilon}^{2}$ & $1423.567^{*}(382)$ & $85.52^{*}(36)$ \\
M3: $\gamma_{t}=\gamma$ & $\lambda_{t}=\lambda ; \sigma_{\varepsilon}^{2}(t)=\sigma_{\varepsilon}^{2}$ & $1414.970^{*}(373)$ & $8.60(9)$ \\
M4: $\lambda_{t}=\lambda$ & $\gamma_{t}=\gamma ; \sigma_{\varepsilon}^{2}(t)=\sigma_{\varepsilon}^{2}$ & $1184.477^{*}(373)$ & 239.09* (9) \\
M5: $\sigma_{\varepsilon}^{2}(t)=\sigma_{\varepsilon}^{2}$ & $\gamma_{t}=\gamma$ & $865.513^{*}(364)$ & $318.96^{*}(9)$ \\
\hline
\end{tabular}

of RE. We note that the standard error of the RE estimates are generally smaller than those of the FE estimates. For example, in the case of regression coefficient size, the standard error of the RE estimate is three times smaller than for the FE estimate. The gross misfit of the model, however, indicated by the chi-square goodness-of-fit tests, raises suspicions on any substantive interpretation of both FE and RE estimates. Clearly, model modification is needed.

\section{Diagnostics for Model Modification}

In the univariate setup, the differences observed between the FE and the RE estimates prompt the researcher to perform a Hausman test to choose between both estimators. In this data, the Hausman test equals $\chi^{2}=37.08, d f=4, p=.00$, and suggests basing the inferences on the FE estimator. A cautious researcher, however, would apply other tests for misspecification before proceeding with the substantive interpretation of the FE estimates. Specifically, the Wald test for heteroscedasticity in the FE model rejects the hypothesis of homoscedasticity of error variances (Wald test is $\chi^{2}=6.4 \times 10^{36}, d f$ $=2268, p=.00$ ). Similarly, the Wooldridge test for autocorrelation (Wooldridge, 2002) rejects the hypothesis of zero first-order serial correlation, $F(1,1867)=45.32, p=.00$. A residuals plot, not shown due to space restrictions, indicates that the assumption of normality of the error term is also violated. Similarly, other regression diagnostic plots, such as the added variable plot used with the demonstration data, could also be applied here, though the number of these plots increases with the number of time-invariant variables, and no clear conclusion is obtained. Overall, these tests would lead us to modify the model by considering not only dropping TI constraints, but also allowing for heteroscedasticity and autocorrelation on the residuals. Models with complex error structures (homoscedasticity and autocorrelation) can be estimated using the mixed command of Stata. ${ }^{15}$ See Snijders and Bosker (2012, chap. 6) for strategies on model specification and testing in the context of the univariate HLM, and Bliese and Ployhart (2002) and Holcomb et al. (2010) on the more specific context of growth-curve models and linear models with random effects at all levels.

In the multivariate approach, the test statistics for model search are based on the simple principle of the overall goodness-of-fit test, and the chi-square difference test for nested models. The MIs are just handy tools that approximate chi-square difference testing for restricted models that are nested to the fitted one. The difference between the chi-square goodness-of-fit test for the model with covariances $\rho(x, u)$ set free, and the other with the same covariances set to zero, is our multivariate version of the Hausman test. The chi-square values for the two models are $1815.39(d f=467)$ and $1769.11(d f=463)$. This yields the chi-square difference $\Delta \chi^{2}=46.28^{16}$ with a difference of degrees of freedom $\Delta d f=4(4$ is the number of time-varying independent variables in the model), and $p=.00$. The test rejects the null hypothesis of zero correlation among the varying intercept and time varying independent variables, the same conclusion obtained when using the classic Hausman test for this data in the univariate approach.

The multivariate RE and FE are both rejected by the chi-square goodness-of-fit test (see the $\chi^{2}$ values in Table 5). Table 6 shows a "bottom-up" strategy (from more to fewer restrictions) for 
model modification within TI. The first column of the table shows the sequence of nested models considered, with an indication of which set of TI restrictions is relaxed in each step. The second column specifies the restrictions associated to each model. The chi-square goodness-of-fit test for each model and the chi-square difference test in each step are presented in the last two columns of the table. In parenthesis we show the corresponding df of the test, an asterisk denoting the test is significant at the $5 \%$ level. The sequence starts with a model that imposes TI in full. Subsets of restrictions of TI are subsequently released according to whether the corresponding chi-square difference test is significant. The choice of the sets of parameter to be freed in each step is left to the research context and the researcher. In panel data, however, the choice made in Table 5 seems reasonable: setting free first the means, then the regression coefficients, and so on, as shown in the table. It also left to the researcher to decide on the number of parameters to be freed in each step; for example, some of the $\beta$ coefficients could be invariant across time while others could vary. In other research contexts, a similar table could be used as a "top-down" strategy, starting with a less restricted model and adding restrictions as we move up. ${ }^{17}$

For our data, in each step the chi-square goodness-of-fit test is significant (indicating the model in that step does not fit the data) and also the chi-square differences are all significant except when testing for the time invariance of $\gamma$. Therefore, the strategy suggests keeping $\gamma$ invariant in the final model. Model search within the family of TI restrictions, however, leaves us with a chi-square goodness-of-fit of $\chi^{2}=865.513(d f=364, p=.00)$, still a nonfitting model. Other modifications of the model therefore seem to be required. Given the type of data, allowing for dynamics in the model is likely to be the course of action.

As noted by one reviewer, this sequence of testing could also be undertaken in the univariate using the mixed of Stata. Minus two times the differences of log likelihoods of two nested models is a likelihood ratio test statistic (see Bliese \& Ployhart, 2002; and Snijders \& Bosker, 2012, chap. 6), that can be used to contrast alternative models and to aid decisions about including specific terms in the model. This approach, however, would be limited to the class of models allowed by mixed. In particular, following the strategy proposed by Bliese and Ployhart (2002) to build and test mixed models, the univariate approach would lead to a model with across time heteroscedastic error terms, which is different from the dynamic model proposed using the "bottom-up" strategy described below. This, therefore, is an example where the univariate and multivariate approaches lead to different final models.

Comparison of models could also be undertaken using the AIC (Akaike, 1974) and BIC (Raftery, 1995) criteria instead of chi-square values. These information criteria provide a rational trade-off between fit and complexity and can be useful to compare nonnested models (Rabe-Hesketh \& Skrondal, 2012, sec. 6.5).

\section{A Dynamic Model}

Inspection of the MIs of the last model fitted in Table 6 points to the significance of autoregressive effects in the dependent variable. This suggests enlarging the model within the family of dynamic panel data models. In particular, we fit the dynamic model represented by equation (6), shown in the path diagram of Figure 2, except that (as a result of the model modification strategy of previous section) we set the parameter $\gamma$ invariant over time and we also allow interaction between time and the varying intercept (loadings $\lambda_{t} s$ varying in $t$ ).

The chi-square goodness-of-fit test for this model is $\chi^{2}=479.406(d f=286, p=.00)$. We see a large decrease in the chi-square value, compared with the decrease in df, but the test still rejects the model. The scaled chi-square goodness-of-fit test (correction for nonnormality, Satorra \& Bentler, $1994)$ gives a $\chi^{2}=415.644(d f=286, p=.00)$, values that still fall in the rejection side. In a further 
Table 7. Estimates (With Standard Errors in Parentheses and Italic) for the Dynamic Panel Data Model: Empirical Data.

\begin{tabular}{|c|c|c|c|c|c|c|c|c|c|c|}
\hline & 1993 & 1994 & 1995 & 1996 & 1997 & 1998 & 1999 & 2000 & 2001 & 2002 \\
\hline \multirow[t]{2}{*}{$\mathrm{roa}_{t-1} \rightarrow \mathrm{roa}_{t}$} & . & & & & & & & & & \\
\hline & & $(0.043)$ & $(0.058)$ & $(0.084)$ & $(0.055)$ & $(0.049)$ & $(0.087)$ & $(0.066)$ & $(0.060)$ & $(0.053)$ \\
\hline \multirow[t]{2}{*}{$\mathrm{cu} \rightarrow \mathrm{roa}_{t}$} & - & $0.140 *$ & $0.05 I^{*}$ & $0.092 *$ & 0.034 & $0.079 *$ & $0.099 *$ & $0.07 I^{*}$ & $0.05 I^{\prime}$ & $0.039 *$ \\
\hline & & $(0.024)$ & $(0.022)$ & $(0.023)$ & $(0.023)$ & $(0.024)$ & $(0.026)$ & $(0.02 I)$ & $(0.022)$ & $(0.019)$ \\
\hline \multirow[t]{2}{*}{$\mathrm{r} \& \mathrm{~d} \rightarrow \mathrm{roa}_{t}$} & - & $-0.353^{*}$ & $-0.268^{*}$ & 0.022 & $-0.366^{*}$ & -0.244 & $-0.501 *$ & $-0.318^{*}$ & $-0.419 *$ & $-0.458 *$ \\
\hline & & & & $(0.150)$ & & $(0$. & $(0.1$ & & & 23) \\
\hline \multirow[t]{2}{*}{$\mathrm{adv} \rightarrow \operatorname{roa}_{t}$} & - & -0.249 & -0.143 & $-0.289 *$ & $-0.249 *$ & $-0.396 *$ & -0.331 & $-0.306 *$ & $-0.319 *$ & $-0.238^{*}$ \\
\hline & & & & & $(0.1 / 4)$ & & & & & $(0.117)$ \\
\hline \multirow[t]{2}{*}{ size $\rightarrow$ roa $_{t}$} & - & & & -0.4 & & & & & & \\
\hline & & $(0.5 I I)$ & 4) & $(0.4$ & $(0.4 / 8)$ & $(0.5$ & $(0.5$ & $(0.4$ & $(0.369)$ & $(0.397)$ \\
\hline \multirow{2}{*}{$\begin{array}{l}\text { founded } \rightarrow \\
\quad \text { roa }_{t}\end{array}$} & - & $-0.026^{*}$ & $-0.026^{*}$ & $-0.026 *$ & $-0.026 *$ & $-0.026 *$ & $-0.026^{*}$ & $-0.026^{*}$ & $-0.026^{*}$ & $-0.026^{*}$ \\
\hline & & (0.C & 0. & $(0.0$ & $(0.012)$ & $(0.012)$ & 10. & (0.C & $(0.012)$ & $(0.012)$ \\
\hline \multirow[t]{2}{*}{$u \rightarrow$ roa $_{t}$} & - & & & $0.752 *$ & $0.714^{*}$ & $0.957 *$ & $1.108^{*}$ & $0.722 *$ & $0.600 *$ & $0.705^{*}$ \\
\hline & & - & $(0.159)$ & (0.198) & $(0.145)$ & $(0.22 I)$ & $(0.2$ & $(0$. & $(0.156)$ & $(0.150)$ \\
\hline \multirow{2}{*}{$\sigma_{u}^{2}$} & - & $26.373^{*}$ & $26.373^{\prime}$ & $26.373^{\prime}$ & $26.373^{\prime}$ & $26.373^{\prime}$ & $26.373 *$ & $26.373^{*}$ & $26.373^{\prime}$ & $26.373 *$ \\
\hline & & & & (8.127) & (8.127) & (8.127) & (8.127) & & (8.127) & (8.127) \\
\hline \multirow[t]{2}{*}{$\alpha$} & - & -0.938 & $\left.5.18\right|^{*}$ & 3.723 & 4.225 & 3.386 & 1.322 & 1.848 & 3.453 & 3.631 \\
\hline & & $(2.632)$ & $(1.965)$ & (2.297) & $(2.46 I)$ & (2.807) & (3.034) & (2.182) & (2.074) & (2.144) \\
\hline \multirow{2}{*}{$\sigma_{\epsilon(t)}^{2}$} & - & $106.497^{*}$ & $101.831 *$ & $89.488 *$ & $82.022 *$ & $64.609 *$ & $64.075^{*}$ & $76.959 *$ & 82.109* & $62.503^{*}$ \\
\hline & & $(10.220)$ & $(I I .22 I)$ & (9.943) & (9.733) & (8.237) & (9.662) & (I I.207) & $(I I .157)$ & (7.530) \\
\hline
\end{tabular}

*Significant at the $5 \%$ level.

search for model improvement, inspection of MIs shows significant values for second-order autoregressive effects in some years, with small EPCs (expected parameter change) in comparison with the first-order effects already introduced. Significant MIs and small EPCs have been argued as indications of nonsubstantial misspecification in the model (Saris, Satorra, \& Van der Veld, 2009); this leads us to halt our search for a better fitting model. We now describe the results of this final model.

Table 7 displays estimates and standard error for all the parameters of the dynamic model. Note that in addition to the dynamics, the TI assumption is not in place, so the table displays parameter estimates varying across time. The table shows a significant autoregressive coefficient $\delta$ for the roat in 8 out of the 10 years, a dynamic effect that was ignored (i.e., set to zero) by the previous static models. With regard to the other model parameters, most of the regression coefficients have the same sign as in the estimates obtained under the static model (see Table 5). Regression coefficients are positive (and significant in 8 out of the 10 years) in the case of $\mathrm{cu}$, and negative in the case of both $r \& d$ and adv (significant values in 7 and 6 years, respectively). The exception, however, is the regression coefficient of size, which was estimated as negative and significant in the static model $(-1.396, z$-value $=-3.84)$ and now is still negative, but not significant. The results derived from this dynamic model show a substantial difference with regard to the impact of size on roa. Note also that the estimates of $\lambda_{t}$ change over time, and that the varying intercept has a smaller variance (although still significant) as compared with the previous FE and RE models; that is, introduction of the autoregressive structure $r o a_{t-1}$ decreases the variance of the unobserved permanent differences across firms. In summary, our search strategy, which started with a very poor fitting static model, suggests a dynamic panel data model that shows time variation in fundamental parameters and an autoregressive structure on the dependent variable roa. 


\section{Discussion and Conclusions}

Two perspectives for analyzing panel data have been discussed and illustrated with demonstration and empirical data: one perspective arranges the data in long format and uses univariate regression methods; the other perspective arranges the data in wide format and uses a set of regression equations. Although few technical articles have compared the two approaches (Allison, 2009; Allison \& Bollen, 1997; Bollen \& Brand, 2010; Ejrnaes \& Holm, 2006; Teachman et al., 2001), we find a body of work in organization research using the univariate approach to panel data which reveals a lack of awareness that a similar analysis could be undertaken using the multivariate approach. By reviewing the two approaches side by side, and by working with the illustrations, we provide an overview of the practice of panel data modeling that we feel would be useful to the wide audience of practitioners, especially in the field of organizational research.

Illustration 1, using demonstration data, first allows the researcher to exemplify the exact equality of results of the univariate and multivariate approaches for the classic FE and RE estimates. Second, it provides evidence of the severe consequences on bias of estimates (not only on misspecified parameters, but also on other correctly specified ones) of ignoring the violation of what has been called the TI assumption, an assumption that may be violated in practice and, thus, as with other assumptions (i.e., random slopes), should be empirically tested (Bliese \& Ployhart, 2002). Third, it allows tools for model modification to be assessed by comparing the ones obtained using the univariate approach (e.g., regression diagnostic tools, added variable plots, deviance tests, etc.) with the ones provided by the multivariate perspective (chi-square goodness-of-fit test, chi-square difference tests, MI, EPC, etc.). Classic test statistics used in the univariate approach to panel data can be replicated in the multivariate approach. For example, the Hausman test for panel data can be framed as a chi-square difference test. Other common tests in the econometrics of panel data (e.g., tests for heteroscedasticity, autocorrelation, etc.) can be performed with the chi-square difference test common in SEM analysis. This may add conceptual simplicity to a plethora of apparently conceptually different tests presently in use in the econometric approach to panel data.

Illustration 2 uses an empirical data set and allows us to compare the two approaches in a setup where we have missing data and uncertainty about which is the true model. Capitalizing on diagnostic and model modification tools available in the multivariate approach using SEM, we provide a step-by-step guide on how to analyze panel data to achieve a better fitting model. The "bottom-up" strategy of model modification proposes a sequence of models (from the most to the least restrictive) that releases the restrictions implied by the TI assumption, and helps applied researchers in the search for a model that significantly improves the fit to the data. Although the choice of the sets of parameters to be freed usually depends on the research context and substantive knowledge, we propose a sequence of models that we believe is reasonable in the case of panel data analysis. In any case, all modifications should make sense theoretically (Green \& Thompson, 2010). The multivariate approach would also simplify the expansion of the model to include measurement error, multiple indicators, lagged regressors, random slopes, and other aspects of SEM. In Illustration 2 we showed how the search for a fitted model, and the need to introduce an autoregressive structure on the dependent variable, led us to enlarge the model within the family of dynamic panel data models. In the multivariate approach this extension can be accomplished in the same frame of models and estimation methods, unlike the univariate approach which requires the use of instrumental variables adapted to this problem (hence, adding conceptual and practical complexities, e.g., Halaby, 2004, p. 541). The article also discusses how the general multivariate panel data model encompasses typical models in organizational research such as repeated-measures ANOVA models and LGC models. A comparison of the models discussed in the article and extensions is shown in Table 8 .

The comparison of the univariate and multivariate approaches to panel data also brings up front practical differences regarding the treatment of missing data that has not received much attention to 


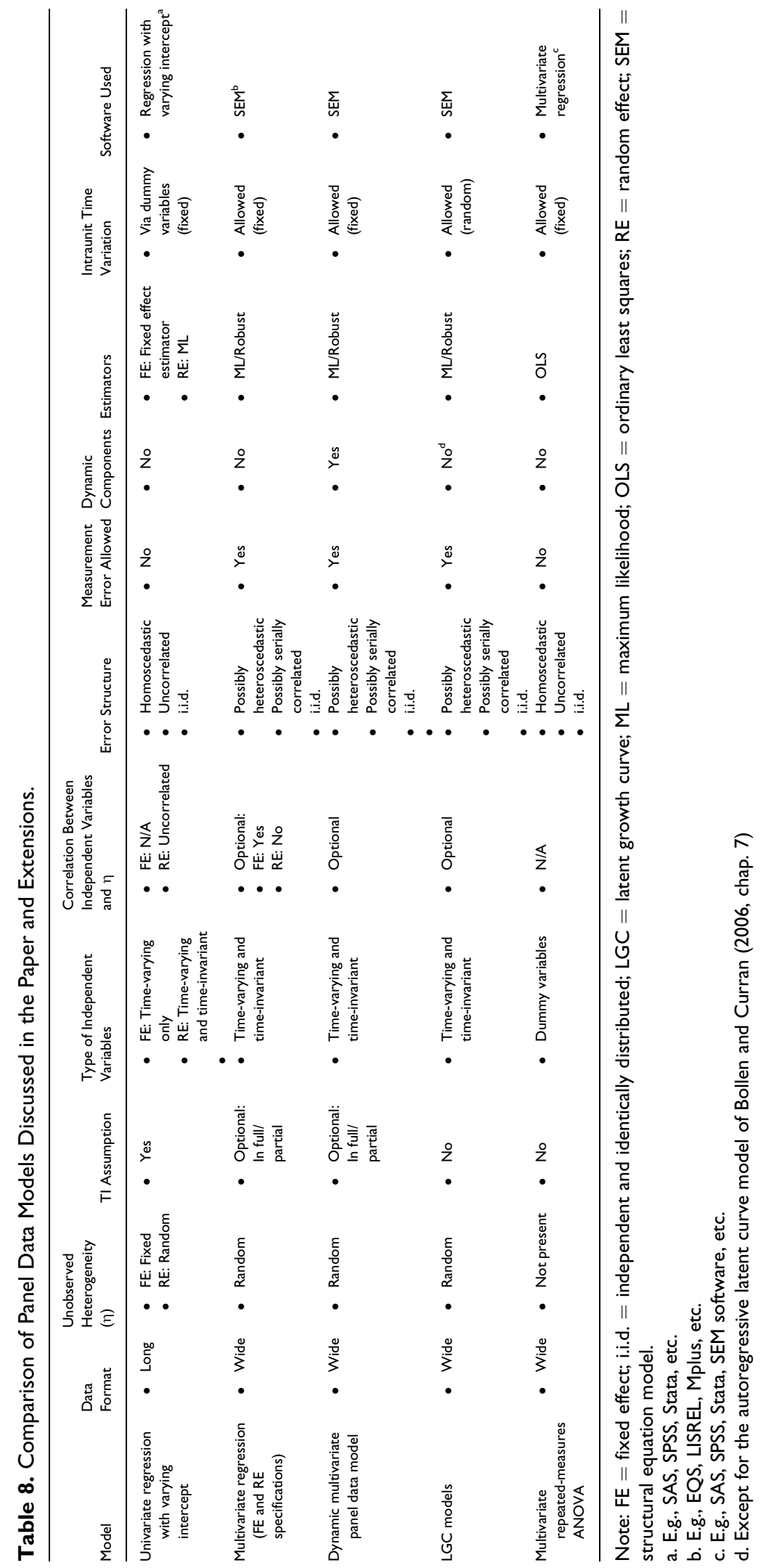


date. It has been argued that the increased number of columns needed to record the data in the wide format makes the multivariate approach unfeasible, and that the univariate approach, using the long format, is more appropriate to deal with panels in which missing data are present (Singer \& Willett, 2003). The illustration with empirical data has demonstrated that nowadays missing data are no longer an issue since we can circumvent the problem with no trouble to the practitioner by using the estimation method of ML with missing data. The missing data issue adds further interest to the comparison of the univariate and multivariate approaches.

To conclude, our comparison of the univariate and multivariate perspectives for panel data should raise awareness among practitioners of the commonalities and differences of the two alternative ways of analyzing panel data. This comparison should also facilitate communication among researchers working with different methodologies. Improved understanding of how the two approaches are related to one another will help them to make better use of each approach. Although we argued that the multivariate perspective excels on conceptual simplicity and in facilitating diagnostic statistics for goodness-of-fit tests and model modification, this should not be understood as a recommendation for the widespread use of one approach over the other. Researchers will find it useful to add the other approach to their repertoire of analytic skills, and we encourage them to do so. We hope the concrete illustrations worked out in the article-with the computed code for the analyses available in the appendix, and the demonstration data replicable from the seed code provided - will help researchers apply the methods discussed in their own panel data settings.

\section{Appendix A: Stata Code for the Analysis of Demonstration Data}

\section{Generation of the Demonstration Data}

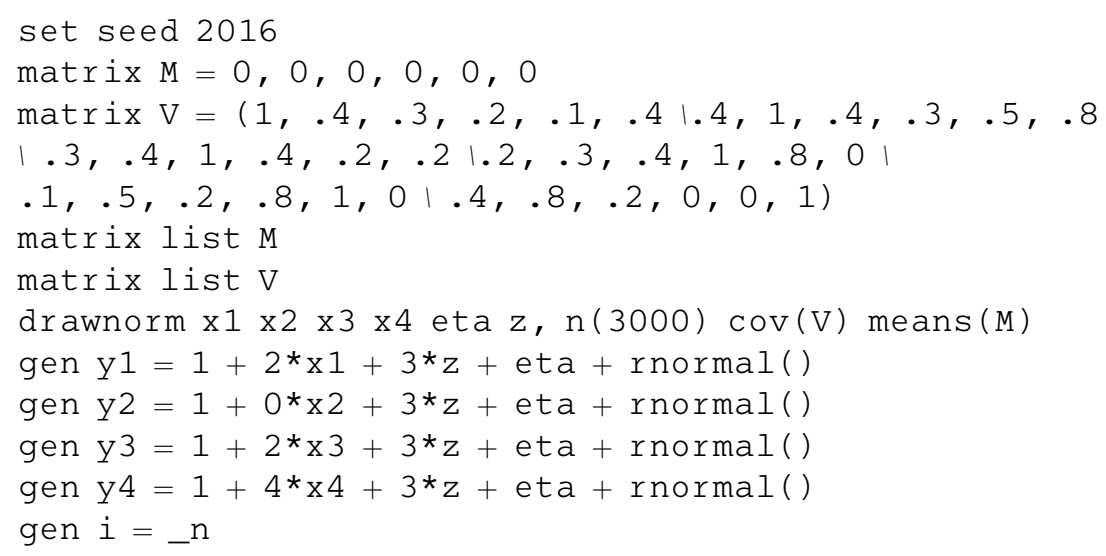

Convert From Wide to Long Format and Declare the Data as a Panel

reshape long $x y, i(i) j(t)$

xtset it

\section{FE (Within Estimator) Model (Table 4)}

xtreg $y \mathrm{x}, \mathrm{fe}$

RE (ML Estimator) Model (Using the xtreg and mixed Options; Table 4)

xtreg y $x$, mle

mixed $y x z|| i:$, variance 


\section{Hausman Test}

quietly xtreg y $\mathrm{x}$, fe estimates store fixed quietly xtreg y $\mathrm{x} z$, re estimates store random hausman fixed random

\section{Multivariate Approach Without the TI Assumption (Table 3)}

sem (u@1 x1 z $\rightarrow$ y1) (u@1 x2 z $\rightarrow$ y2) (u@1 x3 z $\rightarrow$ y3) ///

(u@1 x4 z $\rightarrow$ y4), latent $(u)$ cov(_lexogenous*_oexogenous) /// $\operatorname{cov}(z * u @ 0)$

\section{Multivariate FE (Table 4)}

sem (_cons@alphau@1x1@bz@g->y1) (_cons@alphau@1x2@bz@g->y2) /// (_cons@alphau@1 x3@b z@g->y3) (_cons@alpha u@1 x4@b z@g ->y4) , /// latent (u) var (e._oEn@e) cov(_lex*_oex) cov ( $\left.z^{*} u @ 0\right)$

\section{Multivariate RE (Table 4)}

sem (_cons@alphau@1x1@b z@g->y1) (_cons@alphau@1x2@b z@g->y2) /// (_cons@alphau@1 x3@b z@g->y3) (_cons@alpha u@1 x4@b z@g->y4) , /// latent (u) var (e._oEn@e) cov(_lex*_oex@o)

\section{Univariate Model With Time-Varying Regression Parameters}

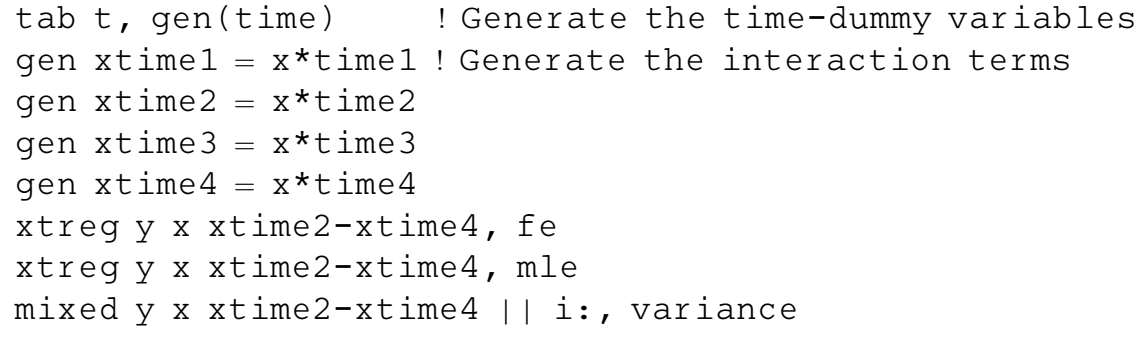

Correlated Random Effect Model (Mundlak, 1978, Approach)

bysort $i$ : egen mean_x $=$ mean $(x)$

mixed y x z mean_x || i:, variance

\section{Univariate Model With Heteroscedastic Disturbances}

mixed y x z || i:, residuals (independent, by $(t)$ ) variance

\section{Univariate Model With First Order Autocorrelated Disturbances}




\section{Appendix B: R Code for the Analysis of Demonstration Data}

\section{Generation of the Demonstration Data}

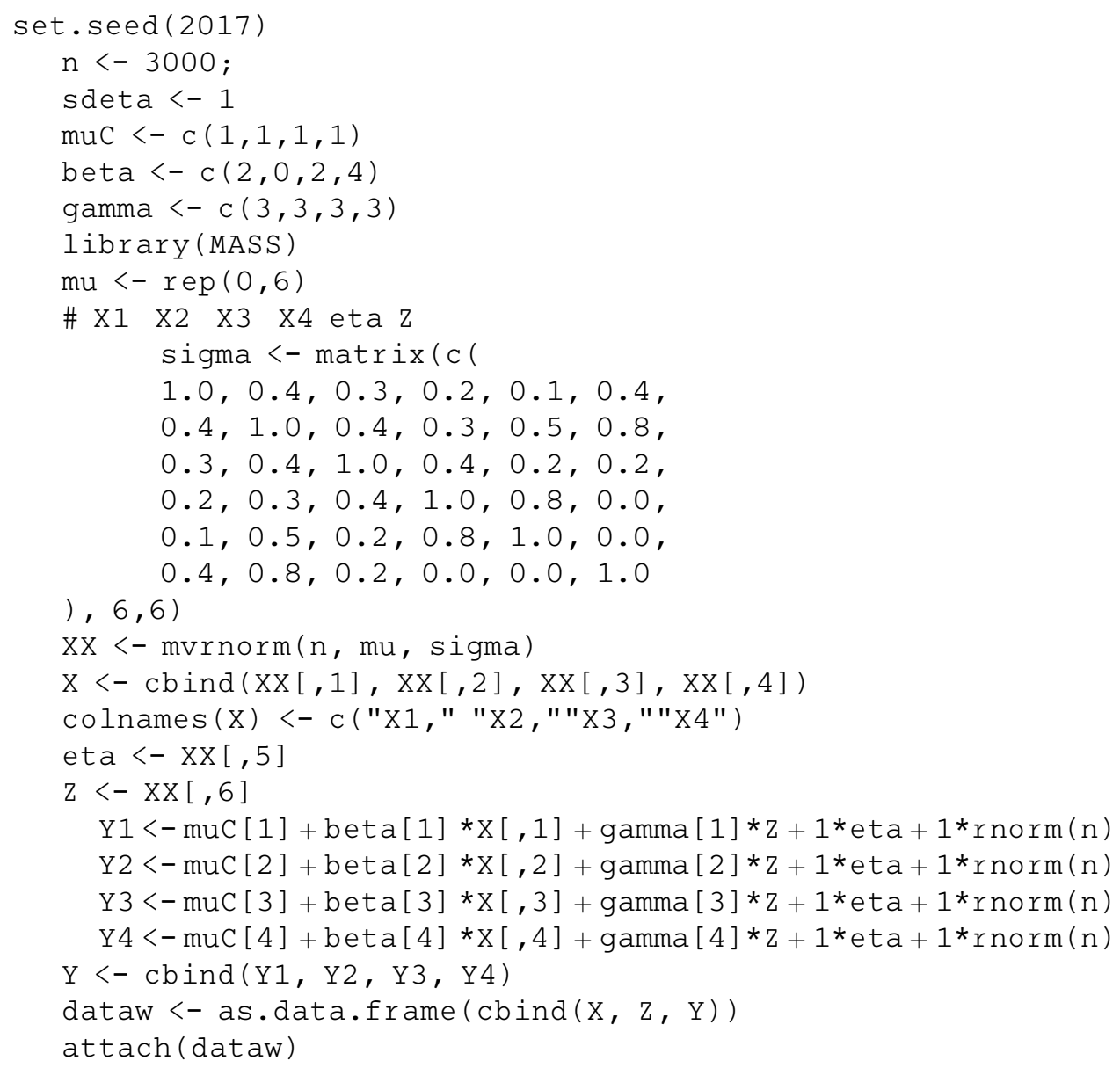

\section{Packages Used}

install.packages("reshape") \# install the reshape package install.packages("plm") \# install the plm package install.packages("nlme") \# install the nlme package install.packages ("lavaan")

\section{Convert From Wide to Long Format}

library (reshape)

datal <- reshape (dataw, direction = "long," varying $=\mathrm{c}(1: 4,6: 9)$, $\mathrm{sep}=" ")$

names (datal) <- c("z," "t," "x," "y," "i")

$\operatorname{attach}($ datal) 
FE (Within Estimator) Model (Using the plm Package; Table 4)

library (plm)

fixed $<-$ plm $(y \sim x$, data $=$ datal, index $=c(" i, "$ "t" $)$, model= "within" ) summary (fixed)

\section{RE (Feasible GLS) Model}

random $<-p l m(y \sim x+z$, data $=$ datal, index $=c(" i, "$ "t" $)$, model $=$ "random")

summary ( $r$ andom)

\section{Hausman Test}

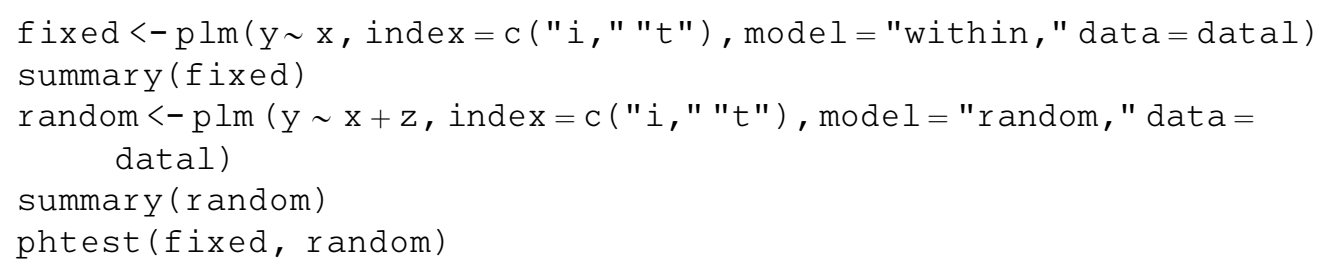

RE (ML Estimator) Model (Using the nlme Package; Table 4)

library (nlme)

random $<-\operatorname{lme}(y \sim x+z, r a n d o m=\sim 1 \mid i$, data $=$ datal $)$

summary ( $r$ andom)

\section{Univariate Model With Heteroscedastic Disturbances}

update (random, weights $=\operatorname{varIdent}($ form $=\sim 1 \mid t))$

\section{Univariate Model With First Order Autocorrelated Disturbances}

update (random, correlation $=\operatorname{corAR} 1())$

\section{Group-Mean Centering (Note 14)}

\# function to compute the group-mean centering of variable

groupcentered <- function $(x$, group $=i)\{$

gm <-aggregate ( $x$, list (group), mean)

$\mathrm{xx}<-\mathrm{x}$

for $(i i$ in 1: $\operatorname{dim}(g m)[1])\{x x[g r o u p==i i]=g m[i i, 2]\}$

\# gcx is group centered $x$

$\operatorname{gcx}<-x-x x$

list $($ gmean $=x x$, gcentered $=$ gcx $)$

\}

\# Computation of the group-mean $x$ and the group-mean centered $x$ $\mathrm{xx}<-$ groupcentered $(\mathrm{x}, \mathrm{i})$ \$gmean

gcx $<-$ groupcentered $(x, i)$ gcentered

\section{Correlated Random Effect Model (Mundlak, 1978, Approach)}

fixedM $<-\operatorname{lme}(y \sim x+z+x x$, random $=\sim 1 \mid i$, data $=$ datal $)$ summary (fixedM) 
Hybrid Model (Allison, 2009)

fixedH $<-\operatorname{lme}(y \sim g c x+z+x x$, random $=\sim 1 \mid i$, data $=$ datal $)$ summary (fixedH)

Group-Mean Centering (Enders \& Tofighi, 2007)

fixedet $<-\operatorname{lme}(y \sim g c x+z$, random $=\sim 1 \mid i$, data $=$ datal $)$

summary (fixedET)

\section{Univariate Model With Time-Varying Regression Parameters}

attach (datal)

\# Generate the time-dummy variables

$\mathrm{d} 1<-1 *(t==1)$

$\mathrm{d} 2<-1 *(t==2)$

$\mathrm{d} 3<-1 *(t==3)$

$\mathrm{d} 4<-1 *(t==4)$

\# Generate the interaction terms

$\mathrm{d} 1 \mathrm{x}<-\mathrm{d} 1 * \mathrm{x}$

$\mathrm{d} 2 \mathrm{x}<-\mathrm{d} 2 * \mathrm{x}$

$\mathrm{d} 3 \mathrm{x}<-\mathrm{d} 33^{*} \mathrm{x}$

$\mathrm{d} 4 \mathrm{x}<-\mathrm{d} 44^{*} \mathrm{x}$

\# Using the function groupcentered defined above:

$\mathrm{d} 2 \mathrm{xc}<-$ groupcentered $(\mathrm{d} 2 \mathrm{x}$, i) \$ gmean

d $3 x c<-g r o u p c e n t e r e d(d 3 x$, i) \$gmean

$\mathrm{d} 4 \mathrm{xc}<-$ groupcentered ( $\mathrm{d} 4 \mathrm{x}$, i) \$gmean

fixedtv $<-\operatorname{lme}(\mathrm{y} \sim \mathrm{x}+\mathrm{xx}+\mathrm{d} 2 \mathrm{x}+\mathrm{d} 3 \mathrm{x}+\mathrm{d} 4 \mathrm{x}+\mathrm{d} 2 \mathrm{xc}+\mathrm{d} 3 \mathrm{xc}+\mathrm{d} 4 \mathrm{xc}+\mathrm{z}$, random $=\sim 1 \mid i$, data $=$ datal)

summary (fixedtv)

\section{Multivariate Approach Without the TI Assumption (Table 3)}

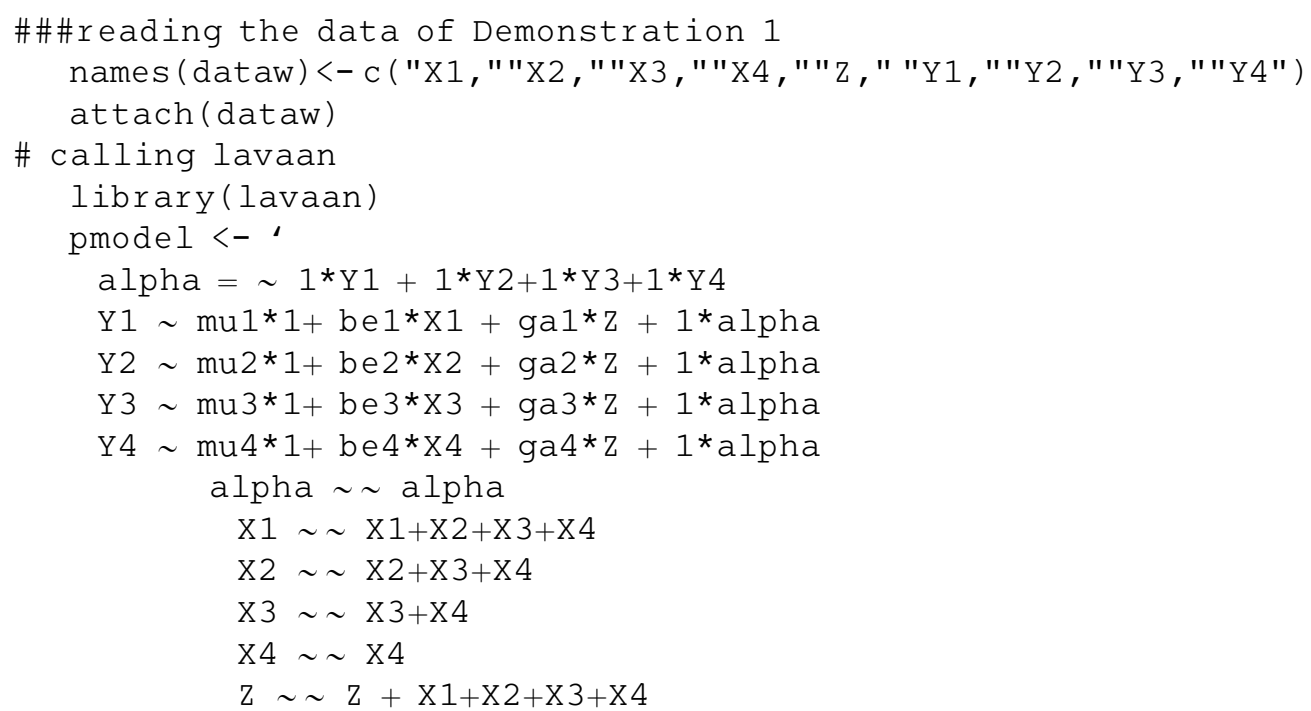




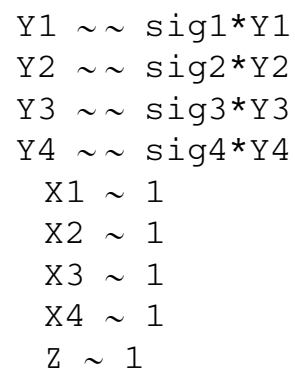

\#\# fixed effect

$$
\begin{aligned}
& \mathrm{X} 1 \sim \operatorname{cor} 1 * a l p h a \\
& \mathrm{X} 2 \sim \operatorname{cor} 2 * a l p h a \\
& \mathrm{X} 3 \sim \operatorname{cor} 3 * a l p h a \\
& \mathrm{X} 4 \sim \operatorname{cor} 4 * a l p h a
\end{aligned}
$$

fit $<-$ lavaan (pmodel, data = dataw) summary (fit)

\section{Multivariate FE (Table 4)}

$\mathrm{Zc}<-\mathrm{Z}-\operatorname{mean}(\mathrm{Z})$ \# note: we center $\mathrm{Z}$, see note in article

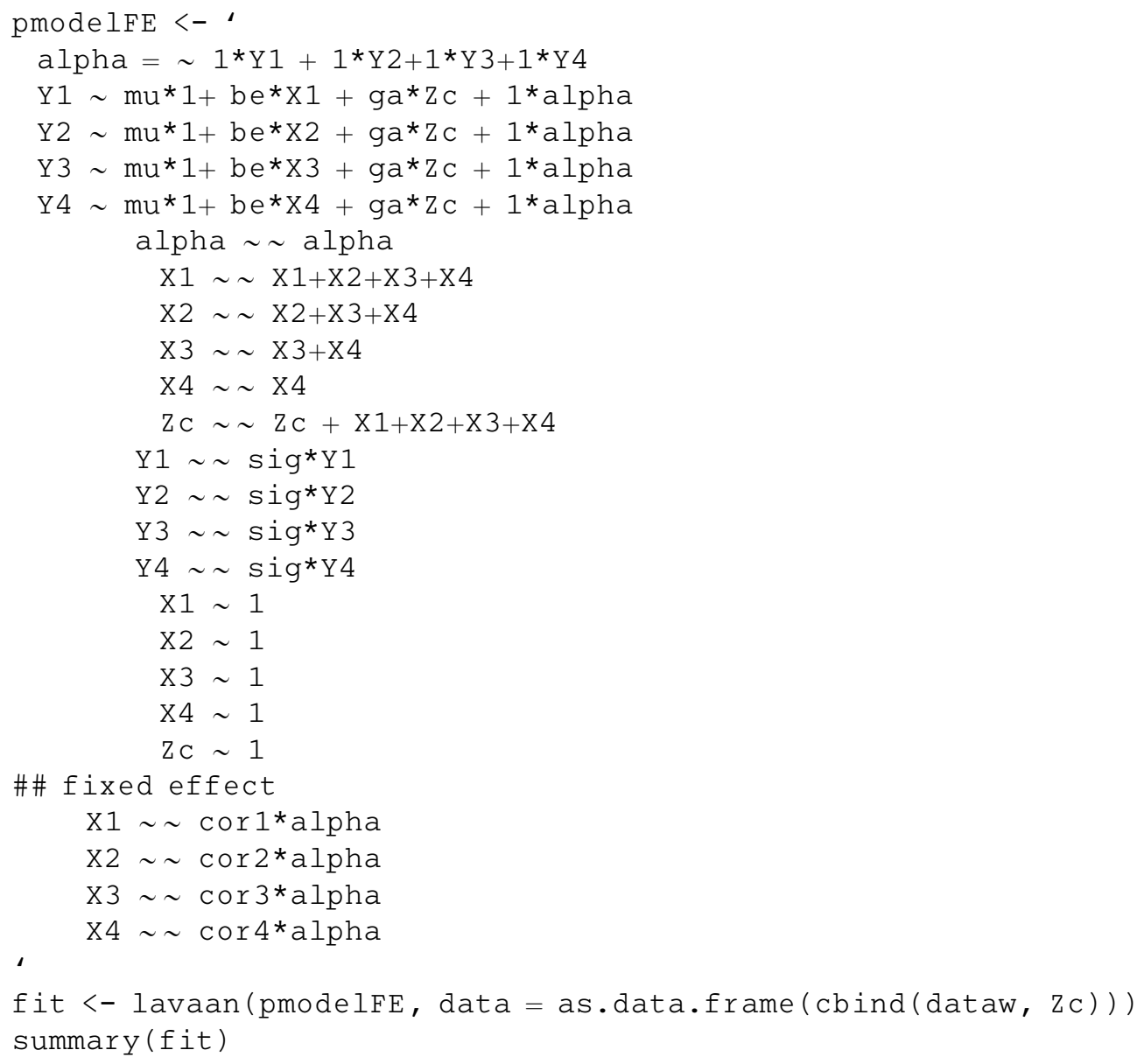




\section{Multivariate RE (Table 4)}

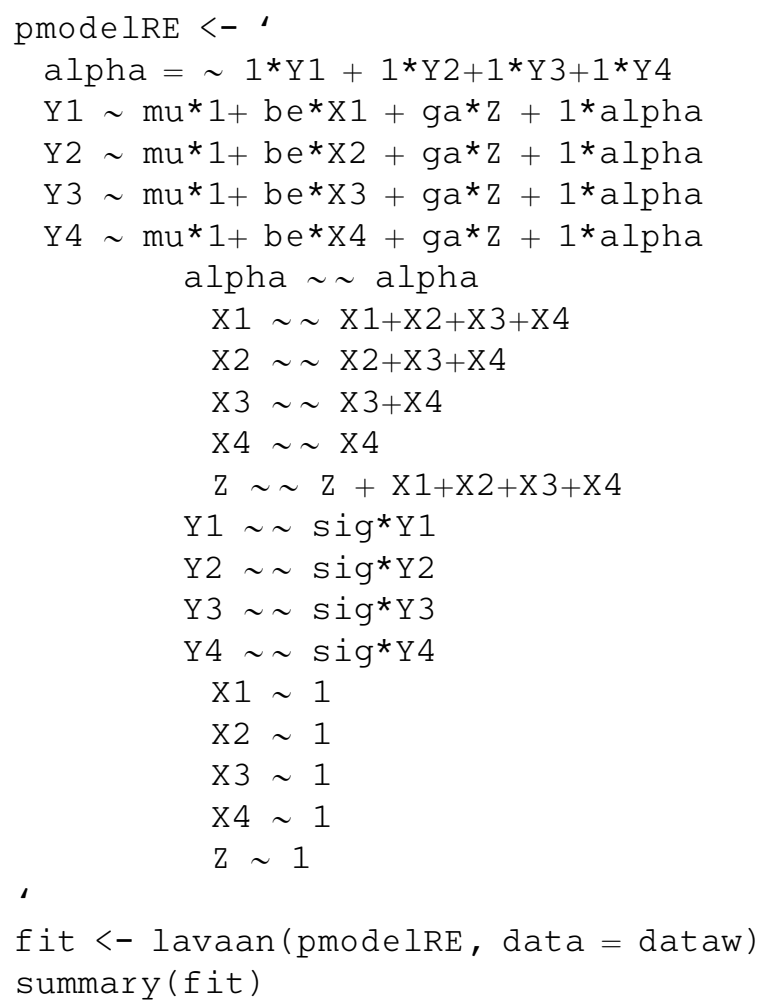

\section{Appendix C: Literature Review on Panel Data Modeling in Organizational Research (20 I3-20 I5): Table and List of Articles.}

Table C. A Classification of Articles Involving Panel Data Analysis (Academy of Management Journal, Journal of Applied Psychology, Journal of Management, and Strategic Management Journal)

\begin{tabular}{|c|c|}
\hline Approach & Studies \\
\hline Univariate & 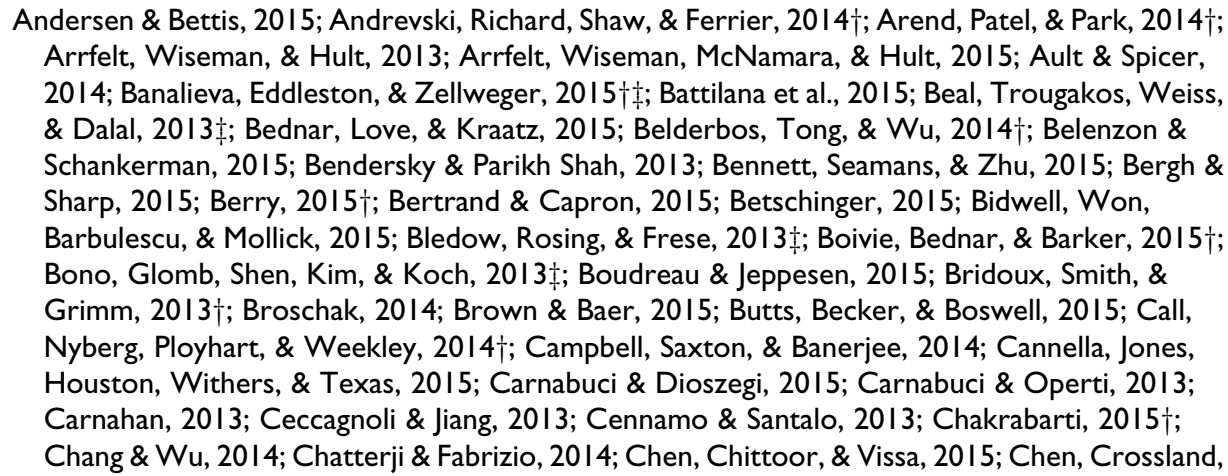 \\
\hline
\end{tabular}


Table C. (continued)

Approach Studies

\& Luo, 2015†; Chen, Luo, Tang, \& Tong, 20I5; Chittoor, Kale, \& Puranam, 2015†; Chizema, Liu, Lu, \& Gao, 20I5; Christensen, Dhaliwal, Boivie, \& Graffin, 20I5; Chung \& Luo, 20I3†; Chung et al., 2015; Conti, 2014; Crossland, Zyung, Hiller, \& Hambrick, 2014; Cumming, Leung, Rui, 2012; Dai, Milkman, Hofmann, \& Staats, 20I5; Damaraju, Barney, \& Makhija, 20I5; Dau, Ayyagari, \& Spencer, 2015; Demirkan, Deeds, \& Demirkan, 2013; Dencker \& Gruber, 20I5; Desai, 2014, 2015; Devers, McNamara, Haleblian, \& Yoder, 2013†; Di Stefano, King, \& Verona, 20I4, 20I5†; Diestel, Rivkin, \& Schmidt, 20I5ł; Diestre \& Rajagopalan, 20I4; Dietz, van Knippenberg, \& Hirst, 20I5; Dong, Liao, Chuang, Zhou, \& Campbell, 20I5; Doshi, Dowell, \& Toffel, 20I3; Dragoni, Park, Soltis, \& Forte-Trammell, 20I4; Drescher, Korsgaard, Welpe, Picot, \& Wigand, 20I4; Durand \& Vergne, 20I5; Eggers, 2014; Engelen, Gupta, Strenger, \& Brettel, 20I5; Ertug, Zajac, Washington, Tosi, \& Val, 20I3; Feldman, Gilson, \& Villalonga, 20I4; Firth, Chen, Kirkman, \& Kim, 2015; Firth, Hollenbeck, Miles, Ilgen, \& Barnes, 20I5; Frank \& Obloj, 20I4†; Fremeth \& Shaver, 20I4; Fuentelsaz, Garrido, \& Maicas, 20I5a †, 20I5b; Funk, 2014; Gamache, McNamara, Mannor, \& Johnson, 20I5†; Ganco, 2013†; Ganco, Ziedonis, \& Agarwal, 2015; Gielnik, Spitzmuller, Schmitt, Klemann, \& Frese, 2015; Godart, Maddux, Shipilov, \& Galinsky, 2015; Greenbaum, Mawritz, \& Piccolo, 2015; Grigoriou \& Rothaermel, 2014; Haas, Criscuolo, \& George, 2015; Hadani \& Schuler, 2013†; Halbesleben, Wheeler, \& Paustian-Underdahl, 20I3; Hallen, Katila, \& Rosenberger, 20I4; Han, Bartol, \& Kim, 20I5t; Harman, Ellington, Surface, \& Thompson, 20I4; Hawk, Pacheco-De-Almeida, \& Yeung, 20I3; Henisz, Dorobantu, \& Nartey, 2014; Hernandez, Sanders, \& Tuschke, 2015†; Hill, Upadhyay, \& Beekun, 2015†; Hoehn-Weiss \& Karim, 2014; Holmes, Miller, Hitt, \& Salmador, 2013; Homan, Buengeler, Eckhoff, van Ginkel, \& Voelpel, 20I5; Howell, Harrison, Burris, \& Detert, 20I5; Hsu \& Ziedonis, 20I3; Huesch, 20I3†; Hülsheger et al., 20I4ł; Hülsheger, Lang, Schewe, \& Zijlstra, 20I5ł; Hutzschenreuter \& Horstkotte, 2013†; Inoue, Lazzarini, \& Musacchio, 20I3; loannou \& Serafeim, 20I5; Johnson, Lanaj, \& Barnes, 20I4ł; Johnson, Rosen, Chang, \& Lin, 20I5; Joshi \& Knight, 20I5; Kang, 20I3; Kapoor \& Klueter, 20I5; Kark, Katz-Navon, \& Delegach, 20I5; Kehoe \& Tzabbar, 20I5†; Khanna, Jones, \& Boivie, 20I4; Khoury, Junkunc, \& Mingo, 20I5; Kim, Hoskisson, \& Lee, 2015†; Kish-Gephart \& Tochman Campbell, 20I5; Kistruck, Qureshi, \& Beamish, 20I3; Koh, Qian, \& Wang, 2014; Krause \& Semadeni, 20I3†; Krishnan, 20I5; Kukenberger, Mathieu, \& Ruddy, 20I5; Lahiri \& Narayanan, 20I3; Lam, Liang, Ashford, \& Lee, 20I5; Lamin, 20I2†; Lecuona \& Reitzig, 20I4; Lee \& Weng, 20I3†; Li \& Liang, 20I5; Li, Qian, \& Yao, 20I5; Li, Zhao, Walter, Zhang, \& Yu, 20I5; Lim \& McCann, 20I3; Lim, 20I5; Lim, Celly, Morse, \& Rowe, 20I3; Liu et al., 20I5; Lorinkova, Pearsall, \& Sims Jr., 20I3; Luksyte, Avery, \& Yeo, 20I5; Mackey, Molloy, \& Morris, 20I4; Madsen \& Rodgers, 20I5†; Malhotra, Zhu, \& Reus, $2015 \dagger$; Manikandan \& Ramachandran, 2015; Markóczy, Li Sun, Peng, Shi, \& Ren, 2013†; Marquis \& Lee, 20I3; Martin, Gomez-Mejia, \& Wiseman, 20I3†; Martin, Gözübüyük, \& Becerra, 2015†; Mathieu, Kukenberger, D’Innocenzo, \& Reilly, 20I5; Mayer, Stadler, \& Hautz, 20I5; Milanov \& Shepherd, 20I3; Miller, Minichilli, \& Corbetta, 20I3†; Minbashian \& Luppino, 20I4; Moatti, Ren, Anand, \& Dussauge, 2015; Mudambi \& Swift, 20l4; Mullins, Bachrach, Rapp, Grewal, \& Beitelspacher, 2014; Nadkarni \& Chen, 2014 †; Nadolska \& Barkema, 2014; Ndofor, Sirmon, \& He, 20I5; Ndofor, Wesley, \& Priem, 20I5; O’Brien \& David, 20I4†; O’Brien, David, Yoshikawa, \& Delios, 20I4; O'Connell \& O'Sullivan, 20I4†; Oc, Bashshur, \& Moore, 20I5; Operti \& Carnabuci, 20I4†; Pacheco \& Dean, 20I5; Pacheco-de-Almeida, Hawk, \& Yeung, 20I $5 \dagger$; Pahnke \& Mcdonald, 2015†; Park \& Ro, 2013†; Park, Sturman, Vanderpool, \& Chan, 20I5; Patel \& Cooper, 20I4; Petkova, Wadhwa, Yao, \& Jain, 20I4; Piening, Baluch, \& Salge, 20I3; Polidoro, 20I3; Quigley \& Hambrick, 20I5; Raithel \& Schwaiger, 20I5; Ray, Ling, \& Barney, 20I3†; Reilly, Nyberg, Maltarich, \& Weller, 20I4†; Ridge, Aime, \& White, 20I5; Rockart \& Dutt, 20I5; Ross \& Sharapov, 20I5; Scott, Garza, \& Conlon, 20I4; Seamans, 2013; Seo, Gamache, Devers, \& Carpenter, 2015; Simon, Hurst, Kelley, \& Judge, 2015; Sleptsov, Anand, \& Vasudeva, 2013; Steensma, Chari, \& Heidl, 20I5; Stettner \& Lavie, 20I4†; Su \& Tsang, 20I4; Sun, Song, \& Lim, 
Table C. (continued)

\begin{tabular}{|c|c|}
\hline Approach & Studies \\
\hline & 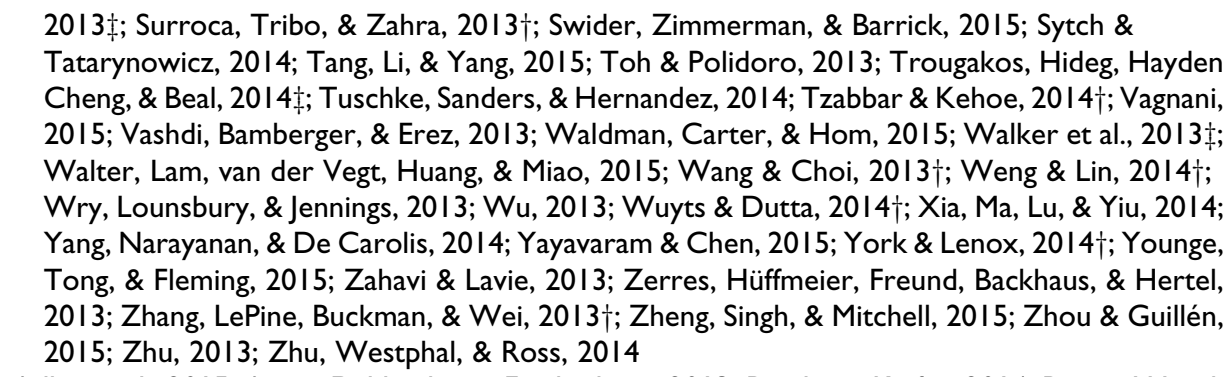 \\
\hline Multivariate & $\begin{array}{l}\text { Adler et al., 20I5; Autio, Dahlander, \& Frederiksen, 20I3; Barclay \& Kiefer, 20I4; Boyce, Wood, } \\
\text { Daly, \& Sedikides, 20I5; Chen et al., 20I3; Colquitt, Baer, Long, \& Halvorsen-Ganepola, 20I4; } \\
\text { Cottrell, Newman, \& Roisman, 20I5; De Jong \& Dirks, 20I2; Duguid \& Thomas-Hunt, 20I4; } \\
\text { Fitza, 20I4; Gabriel \& Diefendorff, 20I5; Halbesleben \& Wheeler, 20I5; Judge, Simon, Hurst, \& } \\
\text { Kelley, 20I4; Kammeyer-Mueller, 20I3; Leroy, Anseel, Gardner, \& Sels, 20I5; Li, Fay, Frese, } \\
\text { Harms, \& Gao, 20I4; Lian, Ferris, Morrison, \& Brown, 20I4; Lievens, De Corte, \& Westerveld, } \\
\text { 20I5; Little, Major, Hinojosa, \& Nelson, 20I5; Liu, Wang, Liao, \& Shi, 20I4ł; Martin, Liao, \& } \\
\text { Campbell, 20I3; Matthews, Wayne, \& Ford, 20I4; Ng \& Feldman, 20I5; Powell \& Butterfield, } \\
\text { 20I5; Restubog, Zagenczyk, Bordia, Bordia, \& Chapman, 20I5; Schaubroeck, Peng, \& Hannah, } \\
\text { 20I3; Smith, Amiot, Smith, Callan, \& Terry, 20I3; Van Kleef, van den Berg, \& Heerdink, 20I5; } \\
\text { Wang et al., 20I3; Welsh, Ordóñez, Snyder, \& Christian, 20I5; Wille \& De Fruyt, 20I4 }\end{array}$ \\
\hline
\end{tabular}

${ }^{\dagger}$ Hausman test has been used to decide between fixed effect and random effect.

${ }^{\ddagger}$ Group-mean centered has been used.

\section{References for Table C}

Adler, A. B., Bliese, P. D., Pickering, M. A., Hammermeister, J., Williams, J., Harada, C., ... Ohlson, C. (2015). Mental skills training with basic combat training soldiers: A group-randomized trial. Journal of Applied Psychology, 100(6), 1752-1764.

Andersen, T. J., \& Bettis, R. A. (2015). Exploring longitudinal risk-return relationships. Strategic Management Journal, 36(8), 1135-1145.

Andrevski, G., Richard, O. C., Shaw, J. D., \& Ferrier, W. J. (2014). Racial diversity and firm performance: The mediating role of competitive intensity. Journal of Management, 40(3), 820-844.

Arend, R. J., Patel, P. C., \& Park, H. D. (2014). Explaining post-IPO venture performance through a knowledgebased view typology. Strategic Management Journal, 35(3), 376-397.

Arrfelt, M., Wiseman, R. M., McNamara, G., \& Hult, G. T. M. (2015). Examining a key corporate role: The influence of capital allocation competency on business unit performance. Strategic Management Journal, 36(7), 1017-1034.

Arrfelt, M., Wiseman, R. M., \& Hult, T. M. G. (2013). Looking backward instead of forward: Aspiration-driven influences on the efficiency of the capital allocation process. Academy of Management Journal, 56(4), 1081-1103.

Ault, J. K., \& Spicer, A. (2014). The institutional context of poverty: State fragility as a predictor of crossnational variation in commercial microfinance lending. Strategic Management Journal, 35(12), 1818-1838.

Autio, E., Dahlander, L., \& Frederiksen, L. (2013). Information exposure, opportunity evaluation, and entrepreneurial action: An investigation of an online user community. Academy of Management Journal, 56(5), 1348-1371.

Banalieva, E. R., Eddleston, K. A., \& Zellweger, T. M. (2015). When do family firms have an advantage in transitioning economies? Toward a dynamic institution-based view. Strategic Management Journal, 36(9), 1358-1377. 
Barclay, L. J., \& Kiefer, T. (2014). Approach or avoid? Exploring overall justice and the differential effects of positive and negative emotions. Journal of Management, 40(7), 1857-1898.

Battilana, J., Djelic, M., Ely, R., Glynn, M. A., Groysberg, B., Haas, M., ... Pratt, M. (2015). Harnessing productive tensions in hybrid organizations: The case of work integration social enterprises. Academy of Management Journal, 58(6), 1658-1685.

Beal, D. J., Trougakos, J. P., Weiss, H. M., \& Dalal, R. S. (2013). Affect spin and the emotion regulation process at work. Journal of Applied Psychology, 98(4), 593-605.

Bednar, M. K., Love, E. G., \& Kraatz, M. (2015). Paying the price? The impact of controversial governance practices on managerial reputation. Academy of Management Journal, 58(6), 1740-1760.

Belderbos, R., Tong, T. W., \& Wu, S. (2014). Multinationality and downside risk: The roles of option portfolio and organization. Strategic Management Journal, 35(1), 88-106.

Belenzon, S., \& Schankerman, M. (2015). Motivation and sorting of human capital in open innovation. Strategic Management Journal, 36(6), 795-820.

Bendersky, C., \& Parikh Shah, N. (2013). The downfall of extraverts and rise of neurotics: The dynamic process of status allocation in task groups. Academy of Management Journal, 56(2), 387-406.

Bennett, V. M., Seamans, R., \& Zhu, F. (2015). Cannibalization and option value effects of secondary markets: Evidence from the US concert industry. Strategic Management Journal, 36(11), 1599-1614.

Bergh, D. D., \& Sharp, B. M. (2015). How far do owners reach into the divestiture process? blockholders and the choice between spin-off and sell-off. Journal of Management, 41(4), 1155-1183.

Berry, H. (2015). Knowledge inheritance in global industries: The impact of parent firm knowledge on the performance of foreign subsidiaries. Academy of Management Journal, 58(5), 1438-1458.

Bertrand, O., \& Capron, L. (2015). Productivity enhancement at home via cross-border acquisitions: The roles of learning and contemporaneous domestic investments. Strategic Management Journal, 36(5), 640-658.

Betschinger, M.-A. (2015). Do banks matter for the risk of a firm's investment portfolio? Evidence from foreign direct investment programs. Strategic Management Journal, 36(8), 1264-1276.

Bidwell, M., Won, S., Barbulescu, R., \& Mollick, E. (2015). I used to work at Goldman Sachs! How firms benefit from organizational status in the market for human capital. Strategic Management Journal, 36(8), 1164-1173.

Bledow, R., Rosing, K., \& Frese, M. (2013). A dynamic perspective on affect and creativity. Academy of Management Journal, 56(2), 432-450.

Boivie, S., Bednar, M. K., \& Barker, S. B. (2015). Social comparison and reciprocity in director compensation. Journal of Management, 41(6), 1578-1603.

Bono, J. E., Glomb, T. M., Shen, W., Kim, E., \& Koch, A. J. (2013). Building positive resources: Effects of positive events and positive reflection on work stress and health. Academy of Management Journal, 56(6), 1601-1627.

Boudreau, K. J., \& Jeppesen, L. B. (2015). Unpaid crowd complementors: The platform network effect mirage. Strategic Management Journal, 36(12), 1761-1777.

Boyce, C. J., Wood, A. M., Daly, M., \& Sedikides, C. (2015). Personality change following unemployment. Journal of Applied Psychology, 100(4), 991-1011.

Bridoux, F., Smith, K. G., \& Grimm, C. M. (2013). The management of resources: Temporal effects of different types of actions on performance. Journal of Management, 39(4), 928-957.

Broschak, J. P. (2014). With or without you: When does managerial exit matter for the dissolution of dyadic market ties? Academy of Management Journal, 57(3), 743-765.

Brown, G., \& Baer, M. (2015). Protecting the turf: The effect of territorial marking on others' creativity. Journal of Applied Psychology, 100(6), 1785-1797.

Butts, M. M., Becker, W. J., \& Boswell, W. R. (2015). Hot buttons and time sinks: The effects of electronic communication during nonwork time on emotions and work-nonwork conflict. Academy of Management Journal, 58(3), 763-788. 
Call, M. L., Nyberg, A. J., Ployhart, R. E., \& Weekley, J. (2014). The dynamic nature of collective turnover and unit performance: The impact of time, quality, and replacements. Academy of Management Journal, 58(4), 1208-1232.

Campbell, B. A., Saxton, B. M., \& Banerjee, P. M. (2014). Resetting the shot clock. Journal of Management, 40(2), 531-556.

Cannella, A. A., Jones, C. D., Houston, S., Withers, M. C., \& Texas, A. (2015). Family- versus lone-foundercontrolled public corporations: Social identity theory and boards of directors. Academy of Management Journal, 58(2), 436-459.

Carnabuci, G., \& Dioszegi, B. (2015). Social networks, cognitive style, and innovative performance: A contingency perspective. Academy of Management Journal, 58(3), 881-905.

Carnabuci, G., \& Operti, E. (2013). Where do firms' recombinant capabilities come from? Intraorganizational networks, knowledge, and firms' ability to innovate through technological recombination. Strategic Management Journal, 34(13), 1591-1613.

Carnahan, S. (2013). Alumni effects and relational advantage: The impact on outsourcing when a buyer hires employees from a supplier's competitors. Academy of Management Journal, 56(6), 1578-1600.

Ceccagnoli, M., \& Jiang, L. (2013). The cost of integrating external technologies: Supply and demand drivers of value creation in the markets for technology. Strategic Management Journal, 34(4), 404-425.

Cennamo, C., \& Santalo, J. (2013). Platform competition: Strategic trade-offs in platform markets. Strategic Management Journal, 34(11), 1331-1350.

Chakrabarti, A. (2015). Organizational adaptation in an economic shock: The role of growth reconfiguration. Strategic Management Journal, 36(11), 1717-1738.

Chang, S.-J., \& Wu, B. (2014). Institutional barriers and industry dynamics. Strategic Management Journal, 35(8), 1103-1123.

Chatterji, A. K., \& Fabrizio, K. R. (2014). Using users: When does external knowledge enhance corporate product innovation? Strategic Management Journal, 35(10), 1427-1445.

Chen, G., Chittoor, R., \& Vissa, B. (2015). Modernizing without westernizing: Social structure and economic action in the Indian financial sector. Academy of ManagementJournal, 58(2), 511-537.

Chen, G., Crossland, C., \& Luo, S. (2015). Making the same mistake all over again: CEO overconfidence and corporate resistance to corrective feedback. Strategic Management Journal, 36(10), 1513-1535.

Chen, G., Luo, S., Tang, Y., \& Tong, J. Y. (2015). Passing probation: Earnings management by interim CEOs and its effect on their promotion prospects. Academy of Management Journal, 58(5), 1389-1418.

Chen, Y., Lance, F. D., Kwan, H. K., Yan, M., Zhou, M., \& Hong, Y. (2013). Self-love's lost labor: A selfenhancement model of workplace incivility. Academy of Management Journal, 56(4), 1199-1219.

Chittoor, R., Kale, P., \& Puranam, P. (2015). Business groups in developing capital markets: Towards a complementarity perspective. Strategic Management Journal, 36(9), 1277-1296.

Chizema, A., Liu, X., Lu, J., \& Gao, L. (2015). Politically connected boards and top executive pay in Chinese listed firms. Strategic Management Journal, 36(6), 890-906.

Christensen, D. M., Dhaliwal, D. S., Boivie, S., \& Graffin, S. D. (2015). Top management conservatism and corporate risk strategies: Evidence from managers' personal political orientation and corporate tax avoidance. Strategic Management Journal, 36(12), 1918-1938.

Chung, C.-N., \& Luo, X. R. (2013). Leadership succession and firm performance in an emerging economy: Successor origin, relational embeddedness, and legitimacy. Strategic Management Journal, 34(3), 338-357.

Chung, Y., Liao, H., Jackson, S. E., Subramony, M., Colakoglu, S., \& Jiang, Y. (2015). Cracking but not breaking: Joint effects of faultline strength and diversity climate on loyal behavior. Academy of Management Journal, 58(5), 1495-1515.

Colquitt, J. A., Baer, M. D., Long, D. M., \& Halvorsen-Ganepola, M. D. K. (2014). Scale indicators of social exchange relationships: A comparison of relative content validity. Journal of Applied Psychology, 99(4), 599-618. 
Conti, R. (2014). Do non-competition agreements lead firms to pursue risky R\&D projects? Strategic Management Journal, 35(8), 1230-1248.

Cottrell, J., Newman, D., \& Roisman, G. (2015). Explaining the Black-White gap in cognitive test scores: Toward a theory of adverse impact. Journal of Applied Psychology, 100(6), 1713-1736.

Crossland, C., Zyung, J., Hiller, N. J., \& Hambrick, D. C. (2014). CEO career variety: Effects on firm-level strategic and social novelty. Academy of Management Journal, 57(3), 652-674.

Cumming, D., Leung, T. Y., \& Rui, O. (2012). Gender diversity and securities fraud. Academy of Management Journal, 58(5), 1572-1593.

Dai, H., Milkman, K., Hofmann, D., \& Staats, B. (2015). The impact of time at work and time off from work on rule compliance: The case of hand hygiene in health care. Journal of Applied Psychology, 100(3), 846-862.

Damaraju, N. L., Barney, J. B., \& Makhija, A. K. (2015). Real options in divestment alternatives. Strategic Management Journal, 36(5), 728-744.

Dau, L. A., Ayyagari, M., \& Spencer, J. (2015). Strategic responses to FDI in emerging markets: Are core members more responsive than peripheral members of business groups? Academy of Management Journal, 58(6), 1869-1894.

De Jong, B. A., \& Dirks, K. T. (2012). Beyond shared perceptions of trust and monitoring in teams: Implications of asymmetry and dissensus. Journal of Applied Psychology, 97(2), 391-406.

Demirkan, I., Deeds, D. L., \& Demirkan, S. (2013). Exploring the role of network characteristics, knowledge quality, and inertia on the evolution of scientific networks. Journal of Management, 39(6), 1462-1489.

Dencker, J. C., \& Gruber, M. (2015). The effects of opportunities and founder experience on new firm performance. Strategic Management Journal, 36(7), 1035-1052.

Desai, V. (2014). The impact of media information on issue salience following other organizations' failures. Journal of Management, 40(3), 893-918.

Desai, V. (2015). Learning through the distribution of failures within an organization: Evidence from heart bypass surgery performance. Academy of Management Journal, 58(4), 1032-1050.

Devers, C. E., McNamara, G., Haleblian, J., \& Yoder, M. E. (2013). Do they walk the talk? Gauging acquiring $\mathrm{CEO}$ and director confidence in the value creation potential of announced acquisitions. Academy of Management Journal, 56(6), 1679-1702.

Diestel, S., Rivkin, W., \& Schmidt, K.-H. (2015). Sleep quality and self-control capacity as protective resources in the daily emotional labor process: Results from two diary studies. Journal of Applied Psychology, 100(3), 809-827.

Diestre, L., \& Rajagopalan, N. (2014). Toward an input-based perspective on categorization: Investor reactions to chemical accidents. Academy of Management Journal, 57(4), 1130-1153

Dietz, B., van Knippenberg, D., \& Hirst, G. (2015). Outperforming whom? A multilevel study of performanceprove goal orientation, performance, and the moderating role of shared team identification. Journal of Applied Psychology, 100(6), 1811-1824.

Di Stefano, G., King, A. A., \& Verona, G. (2014). Kitchen confidential? Norms for the use of transferred knowledge in gourmet cuisine. Strategic Management Journal, 35(11), 1645-1670.

Di Stefano, G., King, A. A., \& Verona, G. (2015). Sanctioning in the wild: Rational calculus and retributive instincts in gourmet cuisine. Academy of Management Journal, 58(3), 906-931.

Dong, Y., Liao, H., Chuang, A., Zhou, J., \& Campbell, E. M. (2015). Fostering employee service creativity: Joint effects of customer empowering behaviors and supervisory empowering leadership. Journal of Applied Psychology, 100(5), 1364-1380.

Doshi, A. R., Dowell, G. W. S., \& Toffel, M. W. (2013). How firms respond to mandatory information disclosure. Strategic Management Journal, 34(10), 1209-1231.

Dragoni, L., Park, H., Soltis, J., \& Forte-Trammell, S. (2014). Show and tell: How supervisors facilitate leader development among transitioning leaders. Journal of Applied Psychology, 99(1), 66-86.

Drescher, M. A., Korsgaard, M. A., Welpe, I. M., Picot, A., \& Wigand, R. T. (2014). The dynamics of shared leadership: Building trust and enhancing performance. Journal of Applied Psychology, 99(5), 771-783. 
Duguid, M. M., \& Thomas-Hunt, M. C. (2014). Condoning stereotyping? How awareness of stereotyping prevalence impacts expression of stereotypes. Journal of Applied Psychology, 100(2), 343-359.

Durand, R., \& Vergne, J.-P. (2015). Asset divestment as a response to media attacks in stigmatized industries. Strategic Management Journal, 36(8), 1205-1223.

Eggers, J. P. (2014). Competing technologies and industry evolution: The benefits of making mistakes in the flat panel display industry. Strategic Management Journal, 35(2), 159-178.

Engelen, A., Gupta, V., Strenger, L., \& Brettel, M. (2015). Entrepreneurial orientation, firm performance, and the moderating role of transformational leadership behaviors. Journal of Management, 41(4), 1069-1097.

Ertug, G., Zajac, E., Washington, M., Tosi, H., \& Val, G. (2013). Getting what you need: How reputation and status affect team performance, hiring, and salaries in the NBA. Academy of Management Journal, 56(2), 407-431.

Feldman, E. R., Gilson, S. C., \& Villalonga, B. (2014). Do analysts add value when they most can? Evidence from corporate spin-offs. Strategic Management Journal, 35(10), 1446-1463.

Firth, B. M., Chen, G., Kirkman, B. L., \& Kim, K. (2015). Newcomers abroad: Expatriate adaptation during early phases of international assignments. Academy of Management Journal, 57(1), 280-300.

Firth, B. M., Hollenbeck, J. R., Miles, J. E., Ilgen, D. R., \& Barnes, C. M. (2015). Same page, different books: Extending representational gaps theory to enhance performance in multiteam systems. Academy of Management Journal, 58(3), 813-835.

Fitza, M. A. (2014). The use of variance decomposition in the investigation of CEO effects: How large must the CEO effect be to rule out chance? Strategic Management Journal, 35(12), 1839-1852.

Frank, D. H., \& Obloj, T. (2014). Firm-specific human capital, organizational incentives, and agency costs: Evidence from retail banking. Strategic Management Journal, 35(9), 1279-1301.

Fremeth, A. R., \& Shaver, J. M. (2014). Strategic rationale for responding to extra-jurisdictional regulation: Evidence from firm adoption of renewable power in the US. Strategic Management Journal, 35(5), 629-651.

Fuentelsaz, L., Garrido, E., \& Maicas, J. P. (2015a). Incumbents, technological change and institutions: How the value of complementary resources varies across markets. Strategic Management Journal, 36(12), 1778-1801.

Fuentelsaz, L., Garrido, E., \& Maicas, J. P. (2015b). A strategic approach to network value in network industries. Journal of Management, 41(3), 864-892.

Funk, R. J. (2014). Making the most of where you are: geography, networks, and innovation in organizations. Academy of Management Journal, 57(1), 193-222.

Gabriel, A. S., \& Diefendorff, J. M. (2015). Emotional labor dynamics: A momentary approach. Academy of Management Journal, 58(6), 1804-1825.

Gamache, D. L., McNamara, G., Mannor, M. J., \& Johnson, R. E. (2015). Motivated to acquire? The impact of CEO regulatory focus on firm acquisitions. Academy of Management Journal, 58(4), 1261-1282.

Ganco, M. (2013). Cutting the Gordian knot: The effect of knowledge complexity on employee mobility and entrepreneurship. Strategic Management Journal, 34(6), 666-686.

Ganco, M., Ziedonis, R. H., \& Agarwal, R. (2015). More stars stay, but the brightest ones still leave: Job hopping in the shadow of patent enforcement. Strategic Management Journal, 36(5), 659-685.

Gielnik, M. M., Spitzmuller, M., Schmitt, A., Klemann, D. K., \& Frese, M. (2015). "I put in effort, therefore I am passionate": Investigating the path from effort to passion in entrepreneurship. Academy of Management Journal, 58(4), 1012-1031.

Godart, F. C., Maddux, W. W., Shipilov, A. V., \& Galinsky, A. D. (2015). Fashion with a foreign flair: Professional experiences abroad facilitate the creative innovations of organizations. Academy of Management Journal, 58(1), 195-220.

Greenbaum, R. L., Mawritz, M. B., \& Piccolo, R. F. (2015). When leaders fail to "walk the talk": Supervisor undermining and perceptions of leader hypocrisy. Journal of Management, 41(3), 929-956.

Grigoriou, K., \& Rothaermel, F. T. (2014). Structural microfoundations of innovation: The role of relational stars. Journal of Management, 40(2), 586-615. 
Haas, M. R., Criscuolo, P., \& George, G. (2015). Which problems to solve? Online knowledge sharing and attention allocation in organization. Academy of Management Journal, 58(3), 680-711.

Hadani, M., \& Schuler, D. A. (2013). In search of El Dorado: The elusive financial returns on corporate political investments. Strategic Management Journal, 34(2), 165-181.

Halbesleben, J. R. B., \& Wheeler, A. R. (2015). To invest or not? The role of coworker support and trust in daily reciprocal gain spirals of helping behavior. Journal of Management, 41(6), 1628-1650.

Halbesleben, J. R. B., Wheeler, A. R., \& Paustian-Underdahl, S. C. (2013). The impact of furloughs on emotional exhaustion, self-rated performance, and recovery experiences. Journal of Applied Psychology, 98(3), 492-503.

Hallen, B. L., Katila, R., \& Rosenberger, J. D. (2014). How do social defenses work? A resource-dependence lens on technology ventures, venture capital investors, and corporate relationships. Academy of Management Journal, 57(4), 1078-1101.

Han, J. H., Bartol, K. M., \& Kim, S. (2015). Tightening up the performance-pay linkage: Roles of contingent reward leadership and profit-sharing in the cross-level influence of individual pay-for-performance. Journal of Applied Psychology, 100(2), 417-430.

Harman, R. P., Ellington, J. K., Surface, E. A., \& Thompson, L. F. (2014). Exploring qualitative training reactions: Individual and contextual influences on trainee commenting. Journal of Applied Psychology, 100(3), 894-916.

Hawk, A., Pacheco-De-Almeida, G., \& Yeung, B. (2013). Fast-mover advantages: Speed capabilities and entry into the emerging submarket of Atlantic Basin LNG. Strategic Management Journal, 34(13), 1531-1550.

Henisz, W. J., Dorobantu, S., \& Nartey, L. J. (2014). Spinning gold: The financial returns to stakeholder engagement. Strategic Management Journal, 35(12), 1727-1748.

Hernandez, E., Sanders, W. G., \& Tuschke, A. (2015). Network defense: Pruning, grafting, and closing to prevent leakage of strategic knowledge to rivals. Academy of Management Journal, 58(4), 1233-1260.

Hill, A. D., Upadhyay, A. D., \& Beekun, R. I. (2015). Do female and ethnically diverse executives endure inequity in the CEO position or do they benefit from their minority status? An empirical examination. Strategic Management Journal, 36(8), 1115-1134.

Hoehn-Weiss, M. N., \& Karim, S. (2014). Unpacking functional alliance portfolios: How signals of viability affect young firms' outcomes. Strategic Management Journal, 35(9), 1364-1385.

Holmes, R. M., Miller, T., Hitt, M. A., \& Salmador, M. P. (2013). The interrelationships among informal institutions, formal institutions, and inward foreign direct investment. Journal of Management, 39(2), 531-566.

Homan, A. C., Buengeler, C., Eckhoff, R. A., van Ginkel, W. P., \& Voelpel, S. C. (2015). The interplay of diversity training and diversity beliefs on team creativity in nationality diverse teams. Journal of Applied Psychology, 100(5), 1456-1467.

Howell, T. M., Harrison, D. A., Burris, E. R., \& Detert, J. R. (2015). Who gets credit for input? Demographic and structural status cues in voice recognition. Journal of Applied Psychology, 100(6), 1765-1784.

Hsu, D. H., \& Ziedonis, R. H. (2013). Resources as dual sources of advantage: Implications for valuing entrepreneurial-firm patents. Strategic Management Journal, 34(7), 761-781.

Huesch, M. D. (2013). Are there always synergies between productive resources and resource deployment capabilities? Strategic Management Journal, 34(11), 1288-1313.

Hülsheger, U. R., Lang, J. W. B., Depenbrock, F., Fehrmann, C., Zijlstra, F. R. H., \& Alberts, H. J. E. M. (2014). The power of presence: The role of mindfulness at work for daily levels and change trajectories of psychological detachment and sleep quality. Journal of Applied Psychology, 99(6), 1113-1128.

Hülsheger, U. R., Lang, J. W. B., Schewe, A. F., \& Zijlstra, F. R. H. (2015). When regulating emotions at work pays off: A diary and an intervention study on emotion regulation and customer tips in service jobs. Journal of Applied Psychology, 100(2), 263-277.

Hutzschenreuter, T., \& Horstkotte, J. (2013). Performance effects of top management team demographic faultlines in the process of product diversification. Strategic Management Journal, 34(6), 704-726. 
Inoue, C. F. K. V., Lazzarini, S. G., \& Musacchio, A. (2013). Leviathan as a minority shareholder: Firm-level implications of state equity purchases. Academy of Management Journal, 56(6), 1775-1801.

Ioannou, I., \& Serafeim, G. (2015). The impact of corporate social responsibility on investment recommendations: Analysts' perceptions and shifting institutional logics. Strategic Management Journal, 36(7), 1053-1081.

Johnson, R. E., Lanaj, K., \& Barnes, C. M. (2014). The good and bad of being fair: Effects of procedural and interpersonal justice behaviors on regulatory resources. Journal of Applied Psychology, 99(4), 635-650.

Johnson, R. E., Rosen, C. C., Chang, C.-H., \& Lin, S.-H. (2015). Getting to the core of locus of control: Is it an evaluation of the self or the environment? Journal of Applied Psychology, 100(5), 1568-1578.

Joshi, A., \& Knight, A. P. (2015). Who defers to whom and why? Dual pathways linking demographic differences and dyadic deference to team effectiveness. Academy of Management Journal, 58(1), 59-84.

Judge, T. A., Simon, L. S., Hurst, C., \& Kelley, K. (2014). What I experienced yesterday is who I am today: Relationship of work motivations and behaviors to within-individual variation in the five-factor model of personality. Journal of Applied Psychology, 99(2), 199-221.

Kammeyer-Mueller, J. (2013). Support, undermining, and newcomer socialization: Fitting in during the first 90 days. Academy of Management Journal, 56(4), 1104-1124.

Kang, J. (2013). The relationship between corporate diversification and corporate social performance. Strategic Management Journal, 34(1), 94-109.

Kapoor, R., \& Klueter, T. (2015). Decoding the adaptability-rigidity puzzle: Evidence from pharmaceutical incumbents' pursuit of gene therapy and monoclonal antibodies. Academy of Management Journal, 58(4), 1180-1207.

Kark, R., Katz-Navon, T., \& Delegach, M. (2015). The dual effects of leading for safety: The mediating role of employee regulatory focus. Journal of Applied Psychology, 100(5), 1332-1348.

Kehoe, R. R., \& Tzabbar, D. (2015). Lighting the way or stealing the shine? An examination of the duality in star scientists' effects on firm innovative performance. Strategic Management Journal, 36(5), 709-727.

Khanna, P., Jones, C. D., \& Boivie, S. (2014). Director human capital, information processing demands, and board effectiveness. Journal of Management, 40(2), 557-585.

Khoury, T. A., Junkunc, M., \& Mingo, S. (2015). Navigating political hazard risks and legal system quality: Venture capital investments in Latin America. Journal of Management, 41(3), 808-840.

Kim, H., Hoskisson, R. E., \& Lee, S.-H. (2015). Why strategic factor markets matter: "New" multinationals' geographic diversification and firm profitability. Strategic Management Journal, 36(4), 518-536.

Kish-Gephart, J. J., \& Tochman Campbell, J. (2015). You don't forget your roots: The influence of CEO social class background on strategic risk taking. Academy of Management Journal, 58(6), 1614-1636.

Kistruck, G. M., Qureshi, I., \& Beamish, P. W. (2013). Geographic and product diversification in charitable organizations. Journal of Management, 39(2), 496-530.

Koh, P.-S., Qian, C., \& Wang, H. (2014). Firm litigation risk and the insurance value of corporate social performance. Strategic Management Journal, 35(10), 1464-1482.

Krause, R., \& Semadeni, M. (2013). Apprentice, departure, and demotion: An examination of the three types of CEO-board chair separation. Academy of Management Journal, 56(3), 805-826.

Krishnan, R. (2015). Status and corporate illegality: Illegal loan recovery practices of commercial banks in India. Academy of Management Journal, 58(5), 1287-1312.

Kukenberger, M. R., Mathieu, J. E., \& Ruddy, T. (2015). A cross-level test of empowerment and process influences on members' informal learning and team commitment. Journal of Management, 41(3), 987-1016.

Lahiri, N., \& Narayanan, S. (2013). Vertical integration, innovation, and alliance portfolio size: Implications for firm performance. Strategic Management Journal, 34(9), 1042-1064.

Lam, C., Liang, J., Ashford, S., \& Lee, C. (2015). Job insecurity and organizational citizenship behavior: Exploring curvilinear and moderated relationships. Journal of Applied Psychology, 100(2), 499-510.

Lamin, A. (2012). The business group as an information resource: An investigation of business group affiliation in the Indian software services industry. Academy of Management Journal, 56(5), 1487-1509. 
Lecuona, J. R., \& Reitzig, M. (2014). Knowledge worth having in "excess": The value of tacit and firm-specific human resource slack. Strategic Management Journal, 35(7), 954-973.

Lee, S.-H., \& Weng, D. H. (2013). Does bribery in the home country promote or dampen firm exports? Strategic Management Journal, 34(12), 1472-1487.

Leroy, H., Anseel, F., Gardner, W. L., \& Sels, L. (2015). Authentic leadership, authentic followership, basic need satisfaction, and work role performance: A cross-level study. Journal of Management, 41(6), 1677-1697.

Li, J., Qian, C., \& Yao, F. K. (2015). Confidence in learning: Inter- and intraorganizational learning in foreign market entry decisions. Strategic Management Journal, 36(6), 918-929.

Li, N., Zhao, H. H., Walter, S. L., Zhang, X.-A., \& Yu, J. (2015). Achieving more with less: extra milers' behavioral influences in teams. Journal of Applied Psychology, 100(4), 1025-1039.

Li, W.-D., Fay, D., Frese, M., Harms, P. D., \& Gao, X. Y. (2014). Reciprocal relationship between proactive personality and work characteristics: A latent change score approach. Journal of Applied Psychology, 99(5), 948-965.

Li, X.-H., \& Liang, X. (2015). A Confucian social model of political appointments among Chinese private-firm entrepreneurs. Academy of Management Journal, 58(2), 592-617.

Lian, H., Ferris, D. L., Morrison, R., \& Brown, D. J. (2014). Blame it on the supervisor or the subordinate? Reciprocal relations between abusive supervision and organizational deviance. Journal of Applied Psychology, 99(4), 651-664.

Lievens, F., De Corte, W., \& Westerveld, L. (2015). Understanding the building blocks of selection procedures: Effects of response fidelity on performance and validity. Journal of Management, 41(6), 1604-1627.

Lim, D. S. K., Celly, N., Morse, E. A., \& Rowe, W. G. (2013). Rethinking the effectiveness of asset and cost retrenchment: The contingency effects of a firm's rent creation mechanism. Strategic Management Journal, $34(1), 42-61$.

Lim, E. N. K. (2015). The role of reference point in CEO restricted stock and its impact on R\&D intensity in high-technology firms. Strategic Management Journal, 36(6), 872-889.

Lim, E. N. K., \& McCann, B. T. (2013). The influence of relative values of outside director stock options on firm strategic risk from a multiagent perspective. Strategic Management Journal, 34(13), 1568-1590.

Little, L. M., Major, V. S., Hinojosa, A. S., \& Nelson, D. L. (2015). Professional image maintenance: How women navigate pregnancy in the workplace. Academy of Management Journal, 58(1), 8-37.

Liu, S., Wang, M., Liao, H., \& Shi, J. (2014). Self-regulation during job search: The opposing effects of employment self-efficacy and job search behavior self-efficacy. Journal of Applied Psychology, 99(6), 1159-1172.

Liu, Y., Wang, M., Chang, C.-H., Shi, J., Zhou, L., \& Shao, R. (2015). Work-family conflict, emotional exhaustion, and displaced aggression toward others: The moderating roles of workplace interpersonal conflict and perceived managerial family support. Journal of Applied Psychology, 100(3), 793-808.

Lorinkova, N. M., Pearsall, M. J., \& Sims, H. P., Jr. (2013). Examining the differential longitudinal performance of directive versus empowering leadership in teams. Academy of Management Journal, 56(2), 573-596.

Luksyte, A., Avery, D. R., \& Yeo, G. (2015). It is worse when you do it: Examining the interactive effects of coworker presenteeism and demographic similarity. Journal of Applied Psychology, 100(4), 1101-1123.

Mackey, A., Molloy, J. C., \& Morris, S. S. (2014). Scarce human capital in managerial labor markets. Journal of Management, 40(2), 399-421.

Madsen, P. M., \& Rodgers, Z. J. (2015). Looking good by doing good: The antecedents and consequences of stakeholder attention to corporate disaster relief. Strategic Management Journal, 36(5), 776-794.

Malhotra, S., Zhu, P., \& Reus, T. H. (2015). Anchoring on the acquisition premium decisions of others. Strategic Management Journal, 36(12), 1866-1876.

Manikandan, K. S., \& Ramachandran, J. (2015). Beyond institutional voids: Business groups, incomplete markets, and organizational form. Strategic Management Journal, 36(4), 598-617. 
Markóczy, L., Li Sun, S., Peng, M. W., Shi, W., \& Ren, B. (2013). Social network contingency, symbolic management, and boundary stretching. Strategic Management Journal, 34(11), 1367-1387.

Marquis, C., \& Lee, M. (2013). Who is governing whom? Executives, governance, and the structure of generosity in large U.S. firms. Strategic Management Journal, 34(4), 483-497.

Martin, G. P., Gomez-Mejia, L. R., \& Wiseman, R. M. (2013). Executive stock options as mixed gambles: Revisiting the behavioral agency model. Academy of Management Journal, 56(2), 451-472.

Martin, G., Gözübüyük, R., \& Becerra, M. (2015). Interlocks and firm performance: The role of uncertainty in the directorate interlock-performance relationship. Strategic Management Journal, 36(2), 235-253.

Martin, S., Liao, H., \& Campbell, E. M. (2013). Comparing empowering leadership and directive leadership on task proficiency and proactivity: A field experiment in the UAE. Academy of Management Journal, 56(5), 1372-1395.

Mathieu, J. E., Kukenberger, M. R., D’Innocenzo, L., \& Reilly, G. (2015). Modeling reciprocal team cohesionperformance relationships, as impacted by shared leadership and members' competence. Journal of Applied Psychology, 100(3), 713-734.

Matthews, R. A., Wayne, J. H., \& Ford, M. T. (2014). A work-family conflict/subjective well-being process model: A test of competing theories of longitudinal effects. Journal of Applied Psychology, 99(6), 1173-1188.

Mayer, M. C. J., Stadler, C., \& Hautz, J. (2015). The relationship between product and international diversification: The role of experience. Strategic Management Journal, 36(10), 1458-1468.

Milanov, H., \& Shepherd, D. A. (2013). The importance of the first relationship: The ongoing influence of initial network on future status. Strategic Management Journal, 34(6), 727-750.

Miller, D., Minichilli, A., \& Corbetta, G. (2013). Is family leadership always beneficial? Strategic Management Journal, 34(5), 553-571.

Minbashian, A., \& Luppino, D. (2014). Short-term and long-term within-person variability in performance: An integrative model. Journal of Applied Psychology, 99(5), 898-914.

Moatti, V., Ren, C. R., Anand, J., \& Dussauge, P. (2015). Disentangling the performance effects of efficiency and bargaining power in horizontal growth strategies: An empirical investigation in the global retail industry. Strategic Management Journal, 36(5), 745-757.

Mudambi, R., \& Swift, T. (2014). Knowing when to leap: Transitioning between exploitative and explorative R\&D. Strategic Management Journal, 35(1), 126-145.

Mullins, R. R., Bachrach, D. G., Rapp, A. A., Grewal, D., \& Beitelspacher, L. S. (2014). You don't always get what you want, and you don't always want what you get: An examination of control-desire for control congruence in transactional relationships, Journal of Applied Psychology, 100(4), 1073-1088.

Nadkarni, S., \& Chen, J. (2014). Bridging yesterday, today, and tomorrow: CEO temporal focus, environmental dynamism, and rate of new product introduction. Academy of Management Journal, 57(6), 1810-1833.

Nadolska, A., \& Barkema, H. G. (2014). Good learners: How top management teams affect the success and frequency of acquisitions. Strategic Management Journal, 35(10), 1483-1507.

Ndofor, H. A., Sirmon, D. G., \& He, X. (2015). Utilizing the firm's resources: How TMT heterogeneity and resulting faultlines affect TMT tasks. Strategic Management Journal, 36(11), 1656-1674.

Ndofor, H. A., Wesley, C., \& Priem, R. L. (2015). Providing CEOs with opportunities to cheat: The effects of complexity-based information asymmetries on financial reporting fraud. Journal of Management, 41(6), 1774-1797.

Ng, T. W. H., \& Feldman, D. C. (2015). Idiosyncratic deals and voice behavior. Journal of Management, 4l(3), 893-928.

O’Brien, J. P., \& David, P. (2014). Reciprocity and R\&D search: Applying the behavioral theory of the firm to a communitarian context. Strategic Management Journal, 35(4), 550-565.

O’Brien, J. P., David, P., Yoshikawa, T., \& Delios, A. (2014). How capital structure influences diversification performance: A transaction cost perspective. Strategic Management Journal, 35(7), 1013-1031. 
Oc, B., Bashshur, M. R., \& Moore, C. (2015). Speaking truth to power: The effect of candid feedback on how individuals with power allocate resources. Journal of Applied Psychology, 100(2), 450-463.

O'Connell, V., \& O'Sullivan, D. (2014). The influence of lead indicator strength on the use of nonfinancial measures in performance management: Evidence from CEO compensation schemes. Strategic Management Journal, 35(6), 826-844.

Operti, E., \& Carnabuci, G. (2014). Public knowledge, private gain: The effect of spillover networks on firms' innovative performance. Journal of Management, 40(4), 1042-1074.

Pacheco, D. F., \& Dean, T. J. (2015). Firm responses to social movement pressures: A competitive dynamics perspective. Strategic Management Journal, 36(7), 1093-1104.

Pacheco-de-Almeida, G., Hawk, A., \& Yeung, B. (2015). The right speed and its value. Strategic Management Journal, 36(2), 159-176.

Pahnke, E. C., \& Mcdonald, R. (2015). Exposed: Venture capital, competitor ties, and entrepreneurial innovation. Academy of Management Journal, 58(5), 1334-1360.

Park, J. K., \& Ro, Y. K. (2013). Product architectures and sourcing decisions: Their impact on performance. Journal of Management, 39(3), 814-846.

Park, S., Sturman, M. C., Vanderpool, C., \& Chan, E. (2015). Only time will tell: The changing relationships between LMX, job performance, and justice. Journal of Applied Psychology, 100(3), 660-680.

Patel, P. C., \& Cooper, D. (2014). Structural power equality between family and non-family TMT members and the performance of family firms. Academy of Management Journal, 57(6), 1624-1649.

Petkova, A. P., Wadhwa, A., Yao, X., \& Jain, S. (2014). Reputation and decision making under ambiguity: A study of U.S. venture capital firms' investments in the emerging clean energy sector. Academy of Management Journal, 57(2), 422-448.

Piening, E. P., Baluch, A. M., \& Salge, T. O. (2013). The relationship between employees' perceptions of human resource systems and organizational performance: Examining mediating mechanisms and temporal dynamics. Journal of Applied Psychology, 98(6), 926-47.

Polidoro, F. (2013). The competitive implications of certifications: The effects of scientific and regulatory certifications on entries into new technical fields. Academy of Management Journal, 56(2), 597-627.

Powell, G. N., \& Butterfield, D. A. (2015). Correspondence between self- and good-manager descriptions. Journal of Management, 41(6), 1745-1773.

Quigley, T. J., \& Hambrick, D. C. (2015). Has the "CEO effect" increased in recent decades? A new explanation for the great rise in America's attention to corporate leaders. Strategic Management Journal, 36(6), 821-830.

Raithel, S., \& Schwaiger, M. (2015). The effects of corporate reputation perceptions of the general public on shareholder value. Strategic Management Journal, 36(6), 945-956.

Ray, G., Ling, X., \& Barney, J. B. (2013). Impact of information technology capital on firm scope and performance: The role of asset characteristics. Academy of Management Journal, 56(4), 1125-1147.

Reilly, G., Nyberg, A. J., Maltarich, M., \& Weller, I. (2014). Human capital flows: Using context-emergent turnover (CET) theory to explore the process by which turnover, hiring, and job demands affect patient satisfaction. Academy of Management Journal, 57(3), 766-790.

Restubog, S. L. D., Zagenczyk, T. J., Bordia, P., Bordia, S., \& Chapman, G. J. (2015). If you wrong us, shall we not revenge? Moderating roles of self-control and perceived aggressive work culture in predicting responses to psychological contract breach. Journal of Management, 41(4), 1132-1154.

Ridge, J. W., Aime, F., \& White, M. A. (2015). When much more of a difference makes a difference: Social comparison and tournaments in the CEO's top team. Strategic Management Journal, 36(4), 618-636.

Rockart, S. F., \& Dutt, N. (2015). The rate and potential of capability development trajectories. Strategic Management Journal, 36(1), 53-75.

Ross, J. M., \& Sharapov, D. (2015). When the leader follows: Avoiding dethronement through imitation. Academy of Management Journal, 58(3), 658-679. 
Schaubroeck, J. M., Peng, A. C., \& Hannah, S. T. (2013). Developing trust with peers and leaders: Impacts on organizational identification and performance during entry. Academy of Management Journal, 56(4), 1148-1168.

Scott, B. A., Garza, A. S., \& Conlon, D. E. (2014). Why do managers act fairly in the first place? A daily investigation of "hot" and "cold" motives and discretion. Academy of Management Journal, 57(6), 1571-1591.

Seamans, R. C. (2013). Threat of entry, asymmetric information, and pricing. Strategic Management Journal, 34(4), 426-444.

Seo, J., Gamache, D. L., Devers, C. E., \& Carpenter, M. A. (2015). The role of CEO relative standing in acquisition behavior and CEO pay. Strategic Management Journal, 36(12), 1877-1894.

Simon, L., Hurst, C., Kelley, K., \& Judge, T. (2015). Understanding cycles of abuse: A multimotive approach. Journal of Applied Psychology, 100(6), 1798-1810.

Sleptsov, A., Anand, J., \& Vasudeva, G. (2013). Relational configurations with information intermediaries: The effect of firm-investment bank ties on expected acquisition performance. Strategic Management Journal, 34(8), 957-977.

Smith, L. G. E., Amiot, C. E., Smith, J. R., Callan, V. J., \& Terry, D. J. (2013). The social validation and coping model of organizational identity development: A longitudinal test. Journal of Management, 39(7), 1952-1978.

Steensma, H. K., Chari, M., \& Heidl, R. (2015). The quest for expansive intellectual property rights and the failure to disclose known relevant prior art. Strategic Management Journal, 36(8), 1186-1204.

Stettner, U., \& Lavie, D. (2014). Ambidexterity under scrutiny: Exploration and exploitation via internal organization, alliances, and acquisitions. Strategic Management Journal, 35(13), 1903-1929.

$\mathrm{Su}, \mathrm{W} .$, \& Tsang, E. W. K. (2014). Product diversification and financial performance: The moderating role of secondary stakeholders. Academy of Management Journal, 58(4), 1128-1148.

Sun, S., Song, Z., \& Lim, V. K. G. (2013). Dynamics of the job search process: Developing and testing a mediated moderation model. Journal of Applied Psychology, 98(5), 771-84.

Surroca, J., Tribo, J. A., \& Zahra, S. A. (2013). Stakeholder pressure on MNEs and the transfer of socially irresponsible practices to subsidiaries. Academy of Management Journal, 56(2), 549-572.

Swider, B. W., Zimmerman, R. D., \& Barrick, M. R. (2015). Searching for the right fit: Development of applicant person-organization fit perceptions during the recruitment process. Journal of Applied Psychology, 100(3), 880-893.

Sytch, M., \& Tatarynowicz, A. (2014). Exploring the locus of invention: The dynamics of network communities and firms' invention productivity. Academy of Management Journal, 57(1), 249-279.

Tang, Y., Li, J., \& Yang, H. (2015). What I see, what I do: How executive hubris affects firm innovation. Journal of Management, 41(6), 1698-1723.

Toh, P. K., \& Polidoro, F. (2013). A competition-based explanation of collaborative invention within the firm. Strategic Management Journal, 34(10), 1186-1208.

Trougakos, J. P., Hideg, I., Hayden Cheng, B., \& Beal, D. J. (2014). Lunch breaks unpacked: The role of autonomy as a moderator of recovery during lunch. Academy of Management Journal, 57(2), 405-421.

Tuschke, A., Sanders, W. M. G., \& Hernandez, E. (2014). Whose experience matters in the boardroom? The effects of experiential and vicarious learning on emerging market entry. Strategic Management Journal, 35(3), 398-418.

Tzabbar, D., \& Kehoe, R. R. (2014). Can opportunity emerge from disarray? An examination of exploration and exploitation following star scientist turnover. Journal of Management, 40(2), 449-482.

Vagnani, G. (2015). Exploration and long-run organizational performance: The moderating role of technological interdependence. Journal of Management, 41(6), 1651-1676.

Van Kleef, G. A., Heerdink, M. W., \& van Kleef, G. A. (2015). The persuasive power of emotions: Effects of emotional expressions on attitude formation and change. Journal of Applied Psychology, 100(4), 1124-1142. 
Vashdi, D. R., Bamberger, P. A., \& Erez, M. (2013). Can surgical teams ever learn? The role of coordination, complexity, and transitivity in action team learning. Academy of Management Journal, 56(4), 945-971.

Waldman, D. A., Carter, M. Z., \& Hom, P. W. (2015). A multilevel investigation of leadership and turnover behavior. Journal of Management, 41(6), 1724-1744.

Walker, H. J., Bauer, T. N., Cole, M. S., Bernerth, J. B., Feild, H. S., \& Short, J. C. (2013). Is this how I will be treated? Reducing uncertainty through recruitment interactions. Academy of Management Journal, 56(5), 1325-1347.

Walter, F., Lam, C. K., van der Vegt, G. S., Huang, X., \& Miao, Q. (2015). Abusive supervision and subordinate performance: Instrumentality considerations in the emergence and consequences of abusive supervision. Journal of Applied Psychology, 100(4), 1056-1072.

Wang, H., \& Choi, J. (2013). A new look at the corporate social-financial performance relationship: The moderating roles of temporal and interdomain consistency in corporate social performance. Journal of Management, 39(2), 416-441.

Wang, M., Liu, S., Liao, H., Gong, Y., Kammeyer-Mueller, J., \& Shi, J. (2013). Can't get it out of my mind: Employee rumination after customer mistreatment and negative mood in the next morning. Journal of Applied Psychology, 98(6), 989-1004.

Welsh, D. T., Ordóñez, L. D., Snyder, D. G., \& Christian, M. S. (2015). The slippery slope: How small ethical transgressions pave the way for larger future transgressions. Journal of Applied Psychology, 100(1), 114-127.

Weng, D. H., \& Lin, Z. (2014). Beyond CEO tenure: The effect of CEO newness on strategic changes. Journal of Management, 40(7), 2009-2032.

Wille, B., \& De Fruyt, F. (2014). Vocations as a source of identity: Reciprocal relations between Big Five personality traits and RIASEC characteristics over 15 years. Journal of Applied Psychology, 99(2), 262-281.

Wry, T., Lounsbury, M., \& Jennings, P. D. (2013). Hybrid vigor: Securing venture capital by spanning categories in nanotechnology. Academy of Management Journal, 57(5), 1309-1333.

$\mathrm{Wu}$, B. (2013). Opportunity costs, industry dynamics, and corporate diversification: Evidence from the cardiovascular medical device industry, 1976-2004. Strategic Management Journal, 34(11), 1265-1287.

Wuyts, S., \& Dutta, S. (2014). Benefiting from alliance portfolio diversity: The role of past internal knowledge creation strategy. Journal of Management, 40(6), 1653-1674.

Xia, J., Ma, X., Lu, J. W., \& Yiu, D. W. (2014). Outward foreign direct investment by emerging market firms: A resource dependence logic. Strategic Management Journal, 35(9), 1343-1363.

Yang, Y., Narayanan, V. K., \& De Carolis, D. M. (2014). The relationship between portfolio diversification and firm value: The evidence from corporate venture capital activity. Strategic Management Journal, 35(13), 1993-2011.

Yayavaram, S., \& Chen, W.-R. (2015). Changes in firm knowledge couplings and firm innovation performance: The moderating role of technological complexity. Strategic Management Journal, 36(3), 377-396.

York, J. G., \& Lenox, M. J. (2014). Exploring the sociocultural determinants of de novo versus de alio entry in emerging industries. Strategic Management Journal, 35(13), 1930-1951.

Younge, K. A., Tong, T. W., \& Fleming, L. (2015). How anticipated employee mobility affects acquisition likelihood: Evidence from a natural experiment. Strategic Management Journal, 36(5), 686-708.

Zahavi, T., \& Lavie, D. (2013). Intra-industry diversification and firm performance. Strategic Management Journal, 34(8), 978-998.

Zerres, A., Hüffmeier, J., Freund, P. A., Backhaus, K., \& Hertel, G. (2013). Does it take two to tango? Longitudinal effects of unilateral and bilateral integrative negotiation training. Journal of Applied Psychology, 98(3), 478-491.

Zhang, Y., LePine, J. A., Buckman, B. R., \& Wei, F. (2013). It's not fair . . or is it? The role of justice and leadership in explaining work stressor-job performance relationships. Academy of Management Journal, 57(3), 675-697. 
Zheng, W., Singh, K., \& Mitchell, W. (2015). Buffering and enabling: The impact of interlocking political ties on firm survival and sales growth. Strategic Management Journal, 36(11), 1615-1636.

Zhou, N., \& Guillén, M. F. (2015). From home country to home base: A dynamic approach to the liability of foreignness. Strategic Management Journal, 36(6), 907-917.

Zhu, D. H. (2013). Group polarization on corporate boards: Theory and evidence on board decisions about acquisition premiums. Strategic Management Journal, 34(7), 800-822.

Zhu, D. H., Westphal, J. D., \& Ross, S. M. (2014). How directors' prior experience with other demographically similar CEOs affects their appointments onto corporate boards and the consequences for CEO compensation. Academy of Management Journal, 57(3), 791-813.

\section{Acknowledgments}

We are thankful for the valuable suggestions and highly constructive comments from associate editor John Antonakis and three anonymous reviewers.

\section{Declaration of Conflicting Interests}

The author(s) declared no potential conflicts of interest with respect to the research, authorship, and/or publication of this article.

\section{Funding}

The author(s) disclosed receipt of the following financial support for the research, authorship, and/or publication of this article: This work has been supported by the Spanish MEC Grants ECO2015-66671-P and ECO2014-59885-P.

\section{Notes}

1. The literature review resulted from a manual revision of the articles obtained by Boolean searches (on fulltext articles) using the keywords "panel," "longitudinal," "repeated measures," "Hausman test," "fixed effects," "random effects," "unobserved heterogeneity," and using the following databases: Business Source Premier for Academy of Management Journal; PsycARTICLES for Journal of Applied Psychology; SAGE Complete A-Z List for Journal of Management; and Willey Online Library for Strategic Management Journal. The search provided an initial list of (418) articles, from which we discarded (171) articles that, in fact, did not involve panel data models (hazard models, survival analysis, cross-section regression, mediation models, etc. were excluded). The final list of articles surveyed is shown in Appendix C, with a classification on whether they use the univariate or the multivariate approach.

2. See LeBreton and Senter (2008) for more detailed discussion on ICC indices, especially in relation to measuring interrater reliability and interrater agreement.

3. For simplicity of the exposition, we consider the case of just one $x$ (time-varying variable) and one $z$ (timeinvariant variable). Extending the case to several $x \mathrm{~s}$ and $z \mathrm{~s}$ is straightforward.

4. With cross-section data (i.e., when $T=1$ ), this is the only option available to the researcher, since lack of repeated observations of $y$ across time confounds $u_{i}$ with the disturbance term $\varepsilon_{i t}$. Provided $u_{i}$ is independent of the variables $x \mathrm{~s}$ and $z \mathrm{~s}$, a model with a constant intercept would still yield consistent OLS estimators of the regression coefficients.

5. We also adhere to Mundlak (1978) in using the term fixed to refer to inferences conditional on the values of those variables in the sample, leaving the researcher to decide whether inferences are made conditionally on the sample at hand, or just refer to the population from where the sample is taken.

6. There are alternative estimation approaches to the fixed effect estimator, such as the first-difference estimator, in which the data are transformed by taking first differences of all the variables, and the least squares dummy variable (LSDV) model, in which a dummy variable is used for each unit (Antonakis, Bendahan, Jacquart, \& Lalive, 2010; Greene, 2003, chap. 13; Pedhazur, 1982, chap. 14). Since these estimators are equivalent, in the illustrations we report only the within estimator. 
7. This is a non-iterative GLS whose estimate of the error variance and serial correlation is resolved using the ICC(1) of the pooled OLS residuals (that is, variance components analysis is applied to the pooled OLS residuals to estimate an ICC from which we infer the error structure used by the feasible GLS). A basic assumption for consistency of the estimate of the ICC from pooled OLS residuals is the zero correlation between the varying intercept and the independent variables at each time point (see Wooldridge, 2013, sec. 14.2, for details).

8. The Stata mixed-regression command mixed with the option $\mathrm{ml}$ produces an identical estimator to the xtreg, mle, but adds more flexibility in modeling the disturbance covariance matrix (e.g., allowing for heteroscedasticity and autocorrelation) and also in model comparison (likelihood ratio tests).

9. An alternative is Allison's (2009, pp. 23-25) hybrid model where, in addition to adding the $\bar{x}_{i}$, the timevarying variables are expressed in deviation from their cluster mean. Therefore, cluster mean centering of the $x \mathrm{~s}$ (but not grand mean centering) solves the problem of inconsistency of the RE estimate of $\beta$ when $\alpha_{i}$ correlates with the independent variables (see Enders \& Tofighi, 2007, for further discussion of centering in mixed models). Both approaches also produce an estimate of $\gamma$; however, this estimate "should be interpreted with caution" (Wooldridge, 2013, p. 498). See Schunck (2013) for a discussion of the two approaches and the limitations of the estimate for $\gamma$ when $\alpha_{i}$ correlates with the independent variables.

10. Using the univariate approach regression coefficients may even be assumed to be random, an extension that is also possible with the multivariate approach, but not discussed in the present article.

11. The same FE estimate (and standard error) would be obtained by the multivariate approach when $z$ is absent from the model, and also when the covariance between $u$ and $z$ is fixed to any arbitrary value.

12. In this specification, the arrows emanating from the constant to 1 to $y_{1}, \ldots, y_{T}$ (means) should be replaced by two arrows, one pointing to $u_{i}$ and the other pointing to the added random slope component.

13. The code for the analysis with this alternative software is available from the authors upon request.

14. For this equality to hold, we used a centered $z$; if $z$ is not centered, then the estimate of $\alpha$ in the univariate and multivariate approaches would differ by the mean of $z$ multiplied by the estimate of $\gamma$.

15. See Appendix A for the Stata code of univariate models with time-varying regression coefficient and heteroscedastic and autocorrelated disturbances. See also Singer and Willett (2003, chap. 7) and RabeHesketh and Skrondal (2012, chap. 6) for applications using Stata.

16. We computed this test statistic using the difference of chi-square model fit values for two nested models, one with the correlations set free but equal over time, and the other with correlations set to zero. Another version of the test statistic could be based on the chi-square difference where the less restricted model sets the correlations $\rho(x, u)$ completely free (i.e., not equal across time). This would lead to a chi-square value of 168.59 with 49 degrees of freedom.

17. See in Bollen and Brand (2010, Table 1) a backward search strategy of fitting models from less to more restrictive.

\section{References}

Aaker, D. A., \& Jacobson, R. (1987). The role of risk in explaining differences in profitability. Academy of Management Journal, 30, 277-296.

Akaike, H. (1974). A new look at the statistical model identification. IEEE Transactions on Automatic Control, 19, 716-723.

Allison, P. D. (2009). Fixed effects regression models. Thousand Oaks, CA: Sage.

Allison, P. D., \& Bollen, K. A. (1997, August). Change scores, fixed effects, and random effects: A structural equation approach. Paper presented at the American Sociological Association Convention, Toronto, Ontario, Canada.

Anderson, T. W., \& Hsiao, C. (1982). Formulation and estimation of dynamic models using panel data. Journal of Econometrics, 18, 47-82.

Andras, T. L., \& Srinivasan, S. S. (2003). Advertising intensity and R\&D intensity: Differences across industries and their impact on firm's performance. International Journal of Business and Economics, 2, 167-176. 
Antonakis, J., Bendahan, S., Jacquart, P., \& Lalive, R. (2010). On making causal claims: A review and recommendations. Leadership Quarterly, 21, 1086-1120.

Arbuckle, J. L. (1996). Full information estimation in the presence of incomplete data. In G. A. Marcoulides \& R. E. Schumacker (Eds.), Advanced structural equation modeling (pp. 243-277). Mahwah, NJ: Lawrence Erlbaum.

Arellano, M. (2003). Panel data econometrics. Oxford, UK: Oxford University Press.

Baltagi, B. H. (2013). Econometric analysis of panel data (5th ed.). Chichester, UK: John Wiley.

Baltes, P. B., \& Nesselroade, J. R. (1979). History and rationale of longitudinal research. In J. R. Nesselroade \& P. B. Baltes (Eds.), Longitudinal research in the study of behavior and development (pp. 1-39). New York, NY: Academic Press.

Bentler, P. M. (2006). EQS 6 structural equations program manual. Encino, CA: Multivariate Software.

Bentler, P. M., \& Satorra, A. (2010). Testing model nesting and equivalence. Psychological Methods, 15, 111-123.

Bergh, D. D. (1993). Watch the time carefully: The use and misuse of time effects in management research. Journal of Management, 19, 683-705.

Bergh, D. D. (1995). Problems with repeated measures analysis: Demonstration with a study of the diversification and performance relationship. Academy of Management Journal, 38, 1962-1708.

Bliese, P. D. (2000). Within-group agreement, non-independence, and reliability: Implications for data aggregation and analyses. In K. J. Klein \& S. W. J. Kozlowski (Eds.), Multilevel theory, research, and methods in organization (pp. 349-381). San Francisco, CA: Jossey-Bass.

Bliese, P. D., \& Ployhart, R. E. (2002). Growth modeling using random coefficient models: Model building, testing and illustrations. Organizational Research Methods, 5, 362-387.

Bollen, K. A. (1989). Structural equations with latent variables. New York, NY: John Wiley.

Bollen, K. A., \& Brand, J. E. (2010). A general panel model with random and fixed effects: A structural equations approach. Social Forces, 89, 1-34.

Bollen, K. A., \& Curran, P. J. (2006). Latent curve models: A structural equation perspective. New York, NY: John Wiley.

Bou, J. C., \& Satorra, A. (2007). The persistence of abnormal returns at industry and firm levels: Evidence from Spain. Strategic Management Journal, 28, 707-722.

Bou, J. C., \& Satorra, A. (2009). Patterns of persistence of abnormal returns: A finite mixture distribution approach. In K. van Montfort, J. Oud, \& A. Satorra (Eds.), Longitudinal models in the behavioral and related sciences (pp. 215-238). Mahwah, NJ: Lawrence Erlbaum.

Bou, J. C., \& Satorra, A. (2010). A multigroup structural equation approach: A demonstration by testing variation of firm profitability across EU samples. Organizational Research Methods, 13, 738-766.

Breusch, T. S., \& Pagan, A. R. (1980). The Lagrange multiplier test and its applications to model specification in econometrics. Review of Economic Studies, 47, 239-253.

Brown, J. S., \& Eisenhardt, K. M. (1995). Product development: Past research, present findings and future directions. Academy of Management Review, 20, 343-378.

Buzzell, R. D., Gale, B. T., \& Sultan, R. G. (1975). Market share-A key to profitability. Harvard Business Review, 53, 97-106.

Capon, N., Farley, J. U., \& Hoenig, S. (1990). Determinants of financial performance: A meta-analysis. Management Science, 36, 1143-1159.

Chamberlain, G. (1982). Multivariate regression models for panel data. Journal of Econometrics, 18, 5-46.

Chan, D. (1998). The conceptualization and analysis of change over time: An integrative approach incorporating longitudinal mean and covariance structure analysis (LMACS) and multiple indicator latent growth modeling (MLGM). Organizational Research Methods, 1, 421-483.

Chou, C. P., Bentler, P. M., \& Pentz, M. A. (1998). Comparisons of two statistical approaches to study growth curves: The multilevel model and the latent curve analysis. Structural Equation Modeling, 5, 247-266. 
Croissant, Y., \& Millo, G. (2008). Panel data econometrics in R: The plm package. Journal of Statistical Software, 27, 1-43.

Davidson, M. L. (1972). Univariate versus multivariate tests in repeated-measures experiments. Psychological Bulletin, 77, 446-452.

Duncan, O. D. (1969). Some linear models for two-wave, two-variable panel analysis. Psychological Bulletin, $72,177-182$

Duncan, T. E., \& Duncan, S. C. (1995). Modeling the processes of development via latent variable growth curve methodology. Structural Equation Modeling, 2, 187-213.

Duncan, T. E., Duncan, S. C., \& Strycker, L. A. (2006). An introduction to latent variable growth curve modeling: Concepts, issues, and applications (2nd ed.). Mahwah, NJ: Lawrence Erlbaum.

Ejrnaes, M., \& Holm, A. (2006). Comparing fixed effects and covariance structure estimators for panel data. Sociological Methods and Research, 35, 35-61.

Enders, C. K., \& Tofighi, D. (2007). Centering predictor variables in cross-sectional multilevel models: A new look at an old issue. Psychological Methods, 12, 121-138.

Farris, P. W., \& Reibstein, D. J. (1979). How prices, ad expenditures, and profits are linked. Harvard Business Review, 57, 173-184.

Finkel, S. E. (1995). Causal analysis with panel data. Thousand Oaks, CA: Sage.

Finn, J. D. (1969). Multivariate analysis of repeated measures data. Multivariate Behavioral Research, 4, 391-413.

Graham, J. W. (2003). Adding missing-data-relevant variables to FIML-based structural equation models. Structural Equation Modeling, 10, 80-100.

Green, S., \& Thompson, M. (2010). Can specification searches be useful for hypothesis generation? Journal of Modern Applied Statistical Methods, 9(1), 16.

Greene, W. H. (2003). Econometric analysis (5th ed.). Upper Saddle River, NJ: Prentice Hall.

Greve, H. R., \& Goldeng, E. (2004). Longitudinal analysis in strategic management. In D. J. Ketchen \& D. D. Bergh (Eds.), Research methodology in strategy and management (Vol. 1, pp. 135-163). Oxford, UK: Elsevier.

Halaby, C. N. (2004). Panel models in sociological research: Theory into practice. Annual Review of Sociology, $30,507-544$

Hamilton, B. H., \& Nickerson, J. A. (2003). Correcting for endongeneity in strategic management research. Strategic Organization, 1, 51-78.

Hausman, J. A. (1978). Specification tests in econometrics. Econometrica, 41, 733-750.

Holcomb, T. R., Combs, J. G., Sirmon, D. G., \& Sexton, J. (2010). Modeling levels and time in entrepreneurship research: An illustration with growth strategies and post-IPO performance. Organizational Research Methods, 13, 348-389.

Hom, P., \& Haynes, K. T. (2007). Applying advanced panel methods to strategic management research: A tutorial. In D. J. Ketchen \& D. D. Bergh (Eds.), Research methodology in strategy and management (Vol. 4, pp. 193-272). Bingley, UK: Emerald.

Hsiao, C. (2014). Analysis of panel data (3rd ed.). New York, NY: Cambridge University Press.

Jöreskog, K. G. (1969). A general approach to confirmatory maximum-likelihood factor analysis. Psychometrika, 34, 183-202.

Jöreskog, K. G. (1978). An econometric model for multivariate panel data. Annals de L'INSEE, 30-31, 355-366.

Jöreskog, K. G., \& Sörbom, D. (2006). LISREL 8.8 for windows [Computer software]. Lincolnwood, IL: Scientific Software.

Kenny, D. A., \& Judd, C. M. (1986). Consequences of violating the independence assumption in analysis of variance. Psychological Bulletin, 99, 422-431.

Kessler, R. C., \& Greenberg, D. F. (1981). Linear panel analysis: Models of quantitative change. New York, NY: Academic Press. 
Kirner, E., Kinkel, S., \& Jaeger, A. (2009). Innovation paths and the innovation performance of low-technology firms-An empirical analysis of German industry. Research Policy, 38, 447-458.

Laird, N. M., \& Ware, J. H. (1982). Random-effects model for longitudinal data. Biometrics, 38, 963-974.

LeBreton, J. M., \& Senter, J. L. (2008). Answers to 20 questions about interrater agreement. Organizational Research Methods, 11, 815-852

Markus, G. B. (1979). Analyzing panel data models. Beverly Hills, CA: Sage.

Mayer, L. S. (1986). On cross-lagged panel models with serially correlated errors. Journal of Business and Economic Statistics, 4, 347-357.

MacCallum, R. C., Kim, C., Malarkey, W. B., \& Kiecolt-Glaser, J. K. (1997). Studying multivariate change using multilevel models and latent curve models. Multivariate Behavioral Research, 32, 215-253.

McArdle, J. J. (2012). Foundational issues in the contemporary modeling of longitudinal trajectories. In B. Laursen, T. D. Little, \& N. A. Card (Eds.), Handbook for developmental research methods (pp. 385-410). New York, NY: Guilford.

McArdle, J. J., \& Epstein, D. B. (1987). Latent growth curves within developmental structural equation models. Child Development, 58, 110-133.

McGahan, A. M., \& Porter, M. E. (1997). How much does industry matter, really? Strategic Management Journal, 18, 15-30.

Meredith, W., \& Tisak, J. (1990). Latent curve analysis. Psychometrika, 55, 107-122.

Misangyi, V. F., LePine, J. A., Algina, J., \& Goeddeke, F. (2006). The adequacy of repeated-measures regression for multilevel research: Comparisons with repeated-measures ANOVA, multivariate repeatedmeasures ANOVA, and multilevel modeling across various multilevel research designs. Organizational Research Methods, 9, 5-28.

Montfort, K., Oud, J. H., \& Satorra, A. (Eds.). (2007). Longitudinal models in the behavioral and related sciences. Mahwah, NJ: Lawrence Erlbaum.

Mundlak, Y. (1978). On the pooling of time series and cross section data. Econometrica, 46, 69-85.

Muthén, L. K., \& Muthén, B. O. (1998-2012). Mplus user's guide (7th ed.). Los Angeles, CA: Muthén \& Muthén.

O’Brien, R. G., \& Kaiser, M. K. (1985). MANOVA method for analyzing repeated measures designs: An extensive primer. Psychological Bulletin, 97, 316-333.

Pedhazur, E. J. (1982). Multiple regression in behavioral research (2nd ed.). New York, NY: Henry Holt.

Phillips, L. W., Chang, D. R., \& Buzzell, R. D. (1983). Product quality, cost position and business performance: A test of some key hypotheses. Journal of Marketing, 47, 26-43.

Pitariu, A. H., \& Ployhart, R. E. (2010). Explaining change: Theorizing and testing dynamic mediated longitudinal relationships. Journal of Management, 36, 405-429.

Ployhart, R. E., \& Vandenberg, R. J. (2010). Longitudinal research: The theory, design, and analysis of change. Journal of Management, 36, 94-120.

Rabe-Hesketh, S., \& Skrondal, A. (2012). Multilevel and longitudinal modeling using Stata (3rd ed.). College Station, TX: Stata Press.

Raftery, A. (1995). Bayesian model selection in social research. Sociological Methodology, 25, 111-163.

Rogan, J. C., Keselman, H. J., \& Mendoza, J. L. (1979). Analysis of repeated measurements. British Journal of Mathematical and Statistical Psychology, 32, 269-286.

Rogosa, D. (1980). A critique of cross-lagged correlation. Psychological Bulletin, 88, 245-258.

Rogosa, D., \& Willett, J. B. (1985). Understanding correlates of change by modeling individual differences in growth. Psychometrika, 50, 203-228.

Rosseel, Y. (2012). lavaan: An R package for structural equation modeling. Journal of Statistical Software, 48, 1-36. Retrieved from www.jstatsoft.org/v48/i02/

Rubin, D. B. (1976). Inference and missing data. Biometrika, 63, 581-592.

Rumelt, R. P. (1991). How much does industry matter? Strategic Management Journal, 12, 167-185. 
Saris, W. E., Satorra, A., \& Sörbom, D. (1987). Detection and correction of specification on errors in structural equation models. In C. C. Clogg (Ed.), Sociological methodology (Vol. 17, pp. 105-129). Newbury Park, CA: Sage.

Saris, W. E., Satorra, A., \& Van der Veld, W. (2009). Testing structural equation models or detection of misspecifications? Structural Equation Modeling, 16, 561-582.

Satorra, A., \& Bentler, P. M. (1990). Model conditions for asymptotic robustness in the analysis of linear relations. Computational Statistics and Data Analysis, 10, 235-249.

Satorra, A., \& Bentler, P. M. (1994). Corrections to test statistics and standard errors in covariance structure analysis. In A. van Eye \& C. C. Clogg (Eds.), Latent variable analysis in developmental research (pp. 285-305). Thousand Oaks, CA: Sage.

Schmalensee, R. (1985). Do markets differ much? American Economic Review, 12, 341-351.

Schunck, R. (2013). Within and between estimates in random-effects models: Advantages and drawbacks of correlated random effects and hybrid models. Stata Journal, 13, 65-76.

Short, J. C., Ketchen, D. J., Bennett, N., \& Du Toit, M. (2006). An examination of firm, industry, and time effects on performance using random coefficients modeling. Organizational Research Methods, 9, 259 -284.

Sinclair, G., Keppler, S., \& Cohen, W. (2000). What's experience got to do with it? Sources of cost reduction in a larger specialty chemical producer. Management Science, 46, 28-45.

Singer, J. D., \& Willett, J. B. (2003). Applied longitudinal data analysis. New York, NY: Oxford University Press.

Snijders, T. A. B., \& Bosker, R. J. (2012). Multilevel Analysis: An introduction to basic and advanced multilevel modeling, Thousand Oaks, CA: Sage.

Sörbom, D. (1989). Model modification. Psychometrika, 54, 371-384.

Stata Corp. 2015. Stata statistical software: Release 14. College Station, TX: Author.

Teachman, J., Duncan, G. J., Yeung, W. J., \& Levy, D. (2001). Covariance structure models for fixed and random effects. Sociological Methods and Research, 30, 271-288.

Thornhill, S. (2006). Knowledge, innovation and firm performance in high- and low-technology regimens. Journal of Business Venturing, 21, 687-703.

Wooldridge, J. M. (2002). Econometric analysis of cross section and panel data. Cambridge, MA: MIT Press.

Wooldridge, J. M. (2013). Introductory econometrics: A modern approach (5th ed.). Mason, OH: SouthWestern Cengage. 